\title{
Transient Receptor Potential Melastatin 8 Channel (TRPM8) Modulation: Cool Entryway for Treating Pain and Cancer
}

M. Jesús Pérez de Vega, ${ }^{1}$ Isabel Gómez-Monterrey, ${ }^{2}$ Antonio Ferrer-Montiel, ${ }^{3}$ Rosario González-Muñiz, ${ }^{* 1}$

${ }^{1}$ Instituto de Química Médica, IQM-CSIC. Juan de la Cierva 3, 28006 Madrid, Spain.

${ }^{2}$ Dipartimento di Farmacia, Università “Federico II" de Napoli, Via D. Montesano 49, 80131, Naples, Italy.

${ }^{3}$ Instituto de Biología Molecular y Celular. Universitas Miguel Hernández. 03202 Alicante, Spain.

Abstract. TRPM8 ion channels, the primary cold sensors in humans, are activated by innocuous cooling $\left(<28{ }^{\circ} \mathrm{C}\right)$ and cooling compounds (menthol, icilin), and are implicated in sensing unpleasant cold stimuli, as well as in mammalian thermoregulation. Over-expression of these thermoregulators in prostate cancer and in other life-threatening tumors, along with their contribution to an increasing number of pathological conditions, opens a plethora of medicinal chemistry opportunities to develop receptor modulators. This Perspective seeks to compile current known modulators for this ion channel, since both agonists and antagonists may be useful for the treatment of most TRPM8-mediated pathologies. We primarily focus on SAR data for the different families of compounds and the pharmacological properties of the most promising ligands. Furthermore, we also address the knowledge about the channel structure, although still in its infancy, and the role of the TRPM8 protein signalplex to channel function and dysfunction. We finally outline the potential future prospects of the challenging TRPM8 drug discovery field. 


\section{INTRODUCTION}

The family of TRP channels comprises 28 members, clustered in 8 subfamilies (TRPA, TRPC, TRPM, TRPML, TRPN, TRPP, TRPV, and TRPY) that function as molecular cellular signal integrators. ${ }^{1-4}$ Among them, the so-called thermoTRPs are activated by different temperatures, ranging from painful levels of heat (TRPV1 and TRPV2), to non-painful warmth (TRPV3 and TRPV4), innocuous cool (TRPM8) and noxious cold (TRPA1). Despite their role as sensors for temperature, these channels also act in response to voltage, mechanical stimuli, and endogenous and exogenous molecules. ${ }^{5-9}$ It has been shown that different syndromes result from mutations or changes in the activities of TRP channels, including sensory deficits, abnormal sensitivity to pain, certain cancers, asthma, and even cardiovascular, gastrointestinal and neurodegenerative diseases. This fact makes TRP channels exciting targets for drug development, although the efforts made in this field, especially in the search for TRPV1 antagonists, have not yet been fully successful, and the first compound in clinical use is still to come. ${ }^{9,10}$ Along with TRPV1 and TRPA1, Transient Receptor Potential Melastatin 8 (TRPM8, also known as Trp-p8 or MCR1) is one of the most studied thermoTRP channels in relation to its physiological and pathological implications, and the search for new modulators occupies the efforts of different pharmaceutical companies and academic groups. Initially identified from the prostate, ${ }^{11}$ TRPM8 channels are widely distributed in different tissues (subsets of sensory neurons innervating skin and mucosae, ${ }^{12-14}$ the male urogenital tract ${ }^{15}$, lung epithelium cells ${ }^{16}$, and artery myocytes ${ }^{17}$ ), although their specific role in many cases still remains to be completely elucidated. This is a $\mathrm{Ca}^{2+}$ permeable, nonselective cation channel that exhibits polymodal gating mechanisms, being activated by innocuous cool to cold temperatures $\left(10-28{ }^{\circ} \mathrm{C}\right),{ }^{18,}{ }^{19}$ membrane 
depolarization, ${ }^{20,}{ }^{21}$ cooling agents like menthol and icilin, ${ }^{20,22}$ and different synthetic molecules. ${ }^{12,23-25}$ The enhanced sensitivity to innocuous cold (allodynia) and to mildly noxious stimuli (hyperalgesia), occurring after nerve injury or inflammation, have been correlated with an augmented expression of TRPM8 in sensory neurons. ${ }^{26,} 27$ Other experimental evidences indicate that activation of TRPM8 channels resulted in attenuating pain in inflammatory and acute pain states, ${ }^{28}$ as commented in more detail in the following section. In recent years, as discussed in section 3, the up-regulation of TRPM8 expression has also been correlated with the evolution of androgen-sensitive prostate cells and other malignancies. ${ }^{11,29}$

As for other ion channels, a point of debate arises from the possibility that both agonists and antagonists can serve for the same therapeutic indication. This comes from the fact that these channels do not have two discrete states only, open (conducting) and closed (non-conducting), but also an inactivated/desensitized state, which after long exposure to agonists or continuous stimulation are not able to conduct ions across, because the channel gate closes (Figure 1) ${ }^{30}$ For TRP channels, calcium entry into the cell seems to be the primary event leading to desensitization. ${ }^{30}$ It has been demonstrated that TRPM 8 channels are activated by $\mathrm{PI}(4,5) \mathrm{P}_{2}$, through putative interactions with the TRP domain, and that cold or menthol increases the apparent affinity of TRPM8 channels for this endogenous ligand. ${ }^{31}$ More importantly, desensitization of TRPM8 receptor, and probably of other TRP channels, is mediated by $\mathrm{PI}(4,5) \mathrm{P}_{2}$ depletion, triggered by a $\mathrm{Ca}^{2+}$-sensitive phospholipase $\mathrm{C}$ (most likely PLC 81 ) stimulated after cell $\mathrm{Ca}^{2+}$ influx, and that resulted in the $\mathrm{PI}(4,5) \mathrm{P}_{2}$ hydrolysis. ${ }^{31,32}$ 


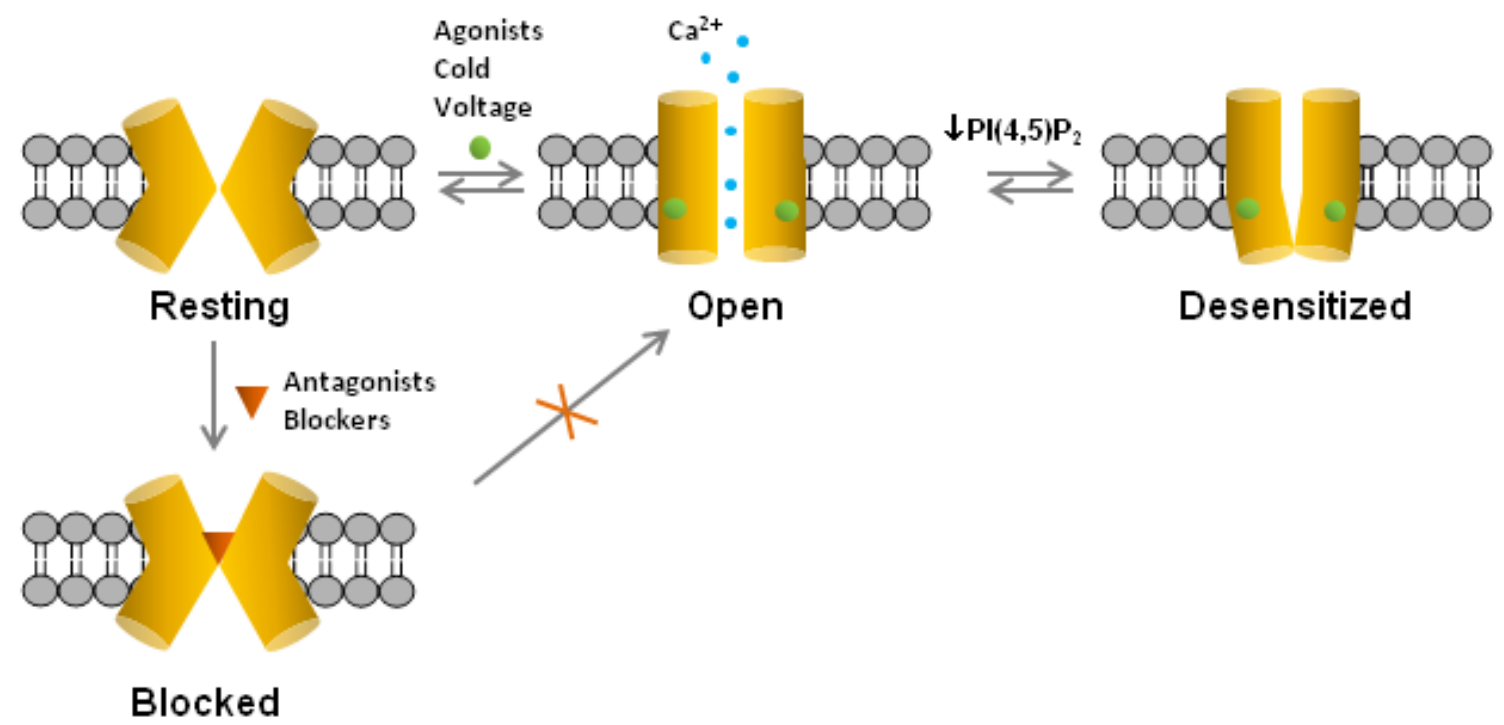

Figure 1. Simplified scheme of TRPM8 channels at different states (resting, open, desensitized, and blocked).

The implications of TRPM8 channels in the above indicated physiopathological conditions underscore their potential as valuable pharmacological targets for therapeutic intervention, not only for the diagnosis/prognosis of prostate cancer and other tumors, but also in the search for innovative analgesics and antitumor agents. ${ }^{10,33}$ Although some comprehensive reviews on the pharmacology and therapeutic potential of TRPM8 modulators have already appeared, ${ }^{12,23-25,33}$ here we offer a general overview of the field, with focus on medicinal chemistry aspects extracted from primary research articles and patents. Sections 5 and 6 are devoted to describe the most important agonist and antagonist chemotypes, with indication of structure-activity relationships, whenever possible, and the in vitro and in vivo pharmacological characterization of the most prominent derivatives. The progression of a few compounds into clinical development will be also commented upon. Some recent contributions related to the indirect assessment of the TRPM8 structure (section 7), and the advanced knowledge of the modulation of these channels by different endogenous molecules (section 8), are also 
included. This information could provide important clues for upcoming drug discovery programs based in this challenging but high potential therapeutic target.

\section{TRPM8, INFLAMMATION AND PAIN}

Pain is defined by the International Association for the Study of Pain (IASP) as an "unpleasant sensory and emotional experience associated with actual or potential tissues damage, or described in terms of such damage". ${ }^{34}$ Pain results from activation of specialized peripheral nerve fibers, called nociceptors, by a noxious stimulus. ${ }^{35}$ The cell bodies of nociceptors are located in the dorsal root ganglia (DRG) for the body and the trigeminal ganglion (TG) for the face, and have both a peripheral and central axonal branch that innervates their target organ and the spinal cord, respectively. These receptors respond to various external stimuli: mechanical (i.e., pressure, tumor growth, incision) thermal (i.e., hot or cold), or chemical (i.e., ischemia or infection). Pain represents a key evolved survival mechanism to detect potentially damaging stimuli and thereby warn of the risk of injury. Unlike acute pain, pain arising after a lesion or disease of the peripheral or central nervous system (inflammatory and neuropathic pain) is often persistent, a chronic state. Hypersensitivity to mechanical, thermal and/or chemical stimulation is one of the hallmarks of inflammatory and neuropathic pain,

which can manifest in the form of allodynia and/or hyperalgesia. ${ }^{36-38}$ Hypersensitivity has been associated with increased excitability of nociceptor neurons as a result of changes in the expression of ion channels, receptors and mediator substances involved in the transduction processes. ${ }^{36,39}$ TRP channels are involved in these processes and play an important role in the first step of primary afferent sensitization. ${ }^{40}$ Therefore, their modulation has been considered, in the last decade, a prominent approach to develop new therapies for chronic pain syndromes. ${ }^{41,42}$ Identifying the mechanisms 
used by nociceptors to transduce noxious cold has lagged behind progress in understanding heat transduction mechanisms. ${ }^{43,44}$

TRPM8 channels are expressed by $\approx 5 \%$ of all somatosensory neurons, including mostly small-diameter, unmyelinated C-fibers, as well as a minor group of lightly myelinated A $\delta$ fibers in dorsal root ganglia (DRG) and trigeminal ganglia (TG), and have been identified as candidates for cold sensing. ${ }^{45-48}$ A subset of the TRPM8-positive cells may co-express TRPV1 and/or CGRP, but are not labeled by other known somatosensory or nociceptive markers (e.g., purinergic receptors, IB4 lectin, or neurotrophin receptors), placing them in their own anatomically and functionally unique subpopulation of primary afferent neurons. ${ }^{49,50}$ In vivo, TRPM8 knockout mice are deficient in detecting innocuous cool temperatures and exhibit a partially defective phenotype in responding to both normal (acute) cold sensation and injury-evoked cold hypersensitivity. However, low temperature $\left(>5^{\circ} \mathrm{C}\right)$ induced cold pain was intact in these animals. ${ }^{51-54}$ Activation of TRPM8 by the agonist menthol or icilin decrease nociceptive response in several animal pain models, including neuropathic pain caused by chronic constriction injury (CCI), inflammatory pain induced by injection of complete Freund's adjuvant (CFA), and a peripheral demyelination model of inflammatory and neuropathic pain. ${ }^{27}$, 55 Also, TRPM8 activation with icilin leads to potent anti-inflammatory effects with decreased mucosal damage in two different models of chemically induced colitis (DSS, TNBS) that are not observed in TRPM8-null mice. ${ }^{55}$ Paradoxically, TRPM8 antagonism may also provide relief from some forms of pain. For example, TRPM8 knockout mice failed to develop cold allodynia after chronic constriction injury or CFA injection. ${ }^{56}$ Similarly, a TRPM8 antagonist reduced cold allodynia in a chronic constriction injury model of chronic neuropathic pain, thus recalling the phenotype of genetic deletion. ${ }^{57}$ Lastly, it has been shown that the administration of TRPM8 agonist menthol induced 
behavioral visceral pain-like responses in a mouse colitis model, which decreased by pre-treatment with a specific TRPM8 channel blocker. ${ }^{58}$ Zou et al., observed also an exacerbated cold hypersensitivity in an orofacial neuropathic pain model rat after treatment with menthol, a cold allodynia/hyperalgesia that was alleviated after administration of a TRPM8 inhibitor. ${ }^{59}$

Recently, different work showed that the ablation of TRPM8 afferents in the adult mouse leads to more profound deficits in cold behaviour compared to TRPM8 knockout animals. ${ }^{60}$ These results suggest the presence of TRPM8-independent transduction mechanisms in TRPM8 neurons, thereby providing cold sensitivity in the absence of TRPM8 channels. Other receptor molecules that have been linked to cold transduction include TRPA $1,{ }^{61}$ channels involved in signal propagation, such as Kv1 and two-pore (K2P) potassium channels, ${ }^{62,63}$ and the sodium channels Nav1.8 and Nav1.9. ${ }^{64,65}$ In addition to acute responses, cold pain associated with inflammation and nerve injury was significantly attenuated in ablated and knockout mice. Moreover, cooling-induced analgesia after nerve injury was abolished in both genotypes. These data confirm previous reports on the involvement of TRPM8 in cooling-induced pain relief, ${ }^{27}$ but show for the first time the absence of analgesia in TRPM8 knockout mice in a neuropathic pain model, and demonstrate that this pain-relief mechanism requires signaling via TRPM8 afferent nerve fibers. Importantly, TRPM8-deficient mice retain normal sensitivity to noxious heat and mechanical stimuli, demonstrating specificity of the observed phenotypes for cold sensation, as well as functional separation of these somatosensory/nociceptive modalities. This observation was confirmed in a recent study with spinal nerve-ligated (SNL) rats treated with a topical TRPM8 agonist, a 1,2,4-triazole derivative (M8-Ag). ${ }^{66}$ This agonist inhibited neuronal responses to 
innocuous and noxious cooling in SNL rats, with no effect in the control group, and did not alter neuronal responses to mechanical, heat or brush stimulation.

Preclinically, TRPM8 has been functionally linked to pain in oxaliplatin-induced ${ }^{67}$ and chronic nerve injury neuropathic pain models, ${ }^{28,68}$ where increased receptor expression and sensitivity to menthol or icilin were observed. In oxaliplatin-treated cancer patients, an increased sensitivity to menthol suggests TRPM8 overexpression or potentiation of its activity. ${ }^{69}$ These preclinical evidences for TRPM8 ion channels as a novel analgesic target have been translated to clinical benefit in patients with cancer-associated neuropathic pain, one of the most feared symptoms in cancer, particularly in terminally ill patients. Recently, Fallon et al. ${ }^{70-72}$ reported the analgesic benefit from the application of topical menthol to treat Chemotherapy-induced Peripheral Neuropathy (CIPN) and Post-mastectomy Pain Syndrome (PMPS). The first clinical results showed that the eighty-two per cent of evaluable patients had an improvement in their total pain scores after 4-6 weeks of treatment. Fifty per cent had a clinically relevant reduction in pain scores of at least $30 \%$, allowing continuation of life prolonging treatment.

Finally, patients with idiopathic detrusor overactivity have increased TRPM8 expression in bladder sensory neurons. ${ }^{73}$ These patients also show involuntary sustained bladder contractions, and reduced bladder threshold volumes in response to installation of ice-cold water into the bladder, an effect absent in healthy adults. ${ }^{74}$ In addition to a potential role in cold detection and pain, TRPM8 has been demonstrated preclinically to have a fundamental homeostatic role in the control of core body temperature, with TRPM8 antagonists causing significant hypothermia. ${ }^{75}$ However, Winchester et al. ${ }^{76}$ have demonstrated that the use of selective TRPM8 antagonists induce analgesia in an experimental model of cold pain in humans, with efficacy equivalent to the 
therapeutically relevant semisynthetic opioid oxycodone and without a concomitant change in core body temperature.

The involvement of TRPM8 channels in migraine is one aspect of the pain field that still remains unclear. Migraine is a very common neurobiological headache disorder associated with nausea, vomiting and photo- and phonophobia symptoms that is caused by increased excitability of the CNS. It ranks among the world's most disabling medical illnesses. ${ }^{77}$ Indirect evidences, such as expression and function of TRP channels in the cortex and trigeminal afferent fibers, suggest a mechanism for the initiation of migraine pain by activation, among others, of TRP channels on meningeal nociceptors after cortical spreading depression (CSD) or local inflammation. ${ }^{78,79}$

Identification of common genetic variants associated with migraine susceptibility has been a real breakthrough in the understanding of migraine molecular bases as well as in determining a potential TRPM8-migraine relationship. ${ }^{80}$ The identification of a TRPM8 gene variant $(2 q 37.1$, rs10166942) is associated with increased susceptibility to common migraine. In 2015, a re-evaluation of key findings from candidate genemigraine association studies provided clear evidence for the involvement of TRPM8 in migraine, and showed no evidence for the participation of TRPVI and TRPV3. ${ }^{81,82}$ The exact role of the TRPM 8 variant is unknown, as is the association of TRPM8 and migraine. However, these data allow hypothesizing that, regardless of being or not a migraine specific susceptibility gene, this TRPM8 variant may have a role in more general pain sensitivity mechanisms, such as the cutaneous allodynia present in the majority of migraine patients.

\section{TRPM8 IN CANCER}


Cancer is a life threatening disease, and even though a plethora of cancer drugs exist for various ailment types, current treatment regimens have important associated problems, and for many cancer types there is still no known cure. In this respect, the number of TRP channels that have been linked to carcinogenesis and tumor progression has considerably increased in recent years. ${ }^{83-87}$ Focusing on TRPM8 channels, they are overexpressed in a number of malignant tumors, especially solid tumors, being involved in different stages of cancer development, proliferation, migration and invasion. ${ }^{88,89}$ In 2001, L. Tsavaler and co-workers reported the identification of a new gene trp-p8, which was preferentially expressed in normal prostate epithelial tissue, and up-regulated in prostate tumor cells. ${ }^{11}$ The transcription polypeptide (1104-mer) of this gene showed a very high homology to a human-melastatin TRP channel identified a year later by G. Reid and M. L. Fonta, ${ }^{90}$ which described a new ionic channel activated by cool and sensitized by menthol, the TRPM8 channel. ${ }^{11}$ Tsavaler et al. observed that the overexpression of TRPM8 in prostate cells correlates with prostate cancer progression. Their studies also revealed the overexpression of trp-p8 gene in a number of neoplastic tissues other than prostatic, like breast, colon, lung, and skin.

The expression of TRPM8 in prostate cells is closely related to androgen receptor (AR) activity, being clearly downregulated in cells in which this activity is cut out. ${ }^{91-93}$ In fact, Prevarskaya and co-workers demonstrated that TRPM8 expression is AR controlled in normal, hyperplasic and cancerous human prostate apical cells, while the loss of TRPM8 expression can be connected to either a high grade of tumor development, with undifferentiated cells (metastasis), or to a AR-independent tumor, where androgen receptor is not expressed..$^{93}$ Moreover, TRPM8 expression has been observed in the androgen-dependent prostate cancer (PCa) cell line LNCaP, but not in the androgen-independent PCa cell lines PC-3 and DU-145. ${ }^{11,91}$ However, expression of 
TRPM8 in the androgen-independent PC-3 cells was reported later by Zhang et al. ${ }^{92}$ Several experiments modulating TRPM8 expression in the androgen-sensitive cell line LNCaP by using menthol and cooling as activators of the channel, and capsazepine as channel antagonist, provided evidence of the role of TRPM8 as mediator of $\mathrm{Ca}^{2+}$ influx and release from intracellular stores, in both plasma membranes and in the endoplasmic reticulum. ${ }^{92,}{ }^{94}$ These results together with those of siRNA experiments confirmed that normal function of TRPM8 is required for tumor cell survival. Later research showed that TRPM8 is expressed both in the plasma membrane, TRPM8 $8_{\mathrm{PM}}$, and in the endoplasmic reticulum, TRPM8 $8_{\mathrm{ER}}$. TRPM8 $8_{\mathrm{PM}}$ channel is found only in highly differentiated prostate epithelial cells, while TRPM $8_{\mathrm{ER}}$ is not dependent on the differentiation status. Further experiments revealed that functional AR seems to be mandatory for TRPM8 $8_{\mathrm{PM}}$ activity, while TRPM8 $8_{\mathrm{ER}}$ activity is independent. They also observed that the transition to PCa upregulated TRPM8 expression is both in plasma membrane and reticulum. It was suggested that TRPM8 $8_{\mathrm{PM}}$ is important for the $\mathrm{Ca}^{2+}$ signaling involved in proliferation, while TRPM8 $8_{\mathrm{ER}}$ can be considered essential in controlling the growth of advanced PCa metastatic cells. ${ }^{95}$ This hypothesis is consistent with the model proposed by Hendriksen et al. in which progression from high-grade PCa to metastasis is mediated by selective downregulation of the AR pathway genes. ${ }^{96}$ It seems clear then, the benefit of androgen-ablation therapy in early stages of prostate cancer, but still there are doubts about the role of TRPM8 in the androgen-independent cell lines, and in advanced grade tumors. Recent work of Zhu et al. proved that artificial overexpression of TRPM8 in the AR-independent cancer PC-3 cell line, in vivo, has a negative effect on the proliferation and angiogenesis progression. These results open new opportunities for the potentiation of TRPM8 channels as treatment for patients in advanced stages of cancer and metastasis. ${ }^{97}$ 
Despite all these results that evidence the correlation of TRPM8 with prostate carcinogenesis and tumor progression, there was still controversy around the idea of whether the aberrant expression of TRPM8 in PCa is the origin or the result of tumor development. In this sense, Pardo and co-workers designed several experiments that shed light on this question. They studied the consequences of TRPM8 silencing, both pharmacologically blocking and siRNA experiments, which showed that proliferation was reduced only in all tumor prostate cells tested, but not in normal prostate cells. It seems that the proliferation of normal cells is not affected by TRPM8 downregulation. These interesting results support the idea that TRPM8 plays a tumor specific role in tumor proliferation instead of being a mere consequence of tumor development. ${ }^{98}$

Concerning diagnoses, the biomarker currently used in clinic for prostate cancer, is the prostate-specific antigen (PSA). However, its usefulness is questionable because PSA can be found in serum samples of both PCa patients, and patients with benign prostatic hyperplasia. Moreover, the PSA levels are quite similar in patients with localized/quiescent PCa and in patients with metastasis. ${ }^{99}$ The higher presence of TRPM8 compared to PSA, in malignant tissue samples in comparison to non-malignant ones, suggests TRPM8 as a useful biomarker for PCa diagnosis. ${ }^{100}$ Bai et al. had found that the TRPM8 levels in urine and blood of patients with metastasis were significantly higher than in patients with localized cancer, that have underwent radical prostatectomy, as well as than those of healthy men. These findings suggest that TRPM8 levels in body fluids can be a useful prognosis biomarker, which will permit to distinguish between clinically localized and metastatic prostate cancer. Their experiments also confirmed the role of TRPM8 in androgen regulated proliferation of prostate cancer cells, although they are in some way contradictory with the results found for TRPM8 expression in organ tissues. $^{101}$ 
The number of tumors in which upregulation of TRPM8 has been detected has increased in the last decade. Tsavaler et al. already reported it in lung, skin, breast and colon cancer tissues. ${ }^{11}$ Since then, it has also been identified in neuroblastoma, osteosarcoma, urothelial carcinoma, in which it was associated with poor survival, and pancreatic adenocarcinoma, where it was shown to correlate with tumor stages. ${ }^{89}$ Chodon et al. found correlation between TRPM8 expression and the breast cancer grade in the MCF-7 cell line, and interestingly they also found correlation with estrogen receptor alpha $(\mathrm{ER} \alpha)$ levels. ${ }^{102}$ This proves that the regulation of TRPM8 in breast cancer cells is hormonal dependent, which is in agreement with the androgen-dependent regulation of TRPM8 in prostate cancer cells. ${ }^{11,93}$ Additionally, experiments performed by Okamoto et al. suggest that TRPM8 channels are functional on the plasma membranes in human oral squamous carcinoma cell lines HSC3 and HSC4. ${ }^{103}$ Experiments to assess the biological response in the presence of TRPM8 agonists and antagonists led to demonstrate that the stimulation of TRPM8 increases MMP-9 activity, while its blockade has the opposite effect, which can be translated in the increased metastatic potential induced by TRPM8. ${ }^{103}$ The group of Yee has demonstrated that TRPM8 is consistently over-expressed in human pancreatic adenocarcinoma cell lines and tissues, and that patients with this type of tumor aberrantly exhibit immunoreactivity against the TRPM8 channel. ${ }^{104,} 105$ They also evidenced that RNAi-mediated silencing of the TRPM8 gene stimulates replicative senescence, thus suggesting that abnormally expressed TRPM8 channels could contribute to pancreatic tumorigenesis. ${ }^{105}$

\section{TRPM8 IN OTHER PATHOLOGICAL CONDITIONS}


Apart from inflammation and cancer, TRPM8 channels are related to other pathological conditions, although they have been less studied and their role is less established. ${ }^{85}$ For instance, there is evidence that link TRPM8 channels to respiratory disorders. Thus, the mitigating effects of menthol in the irritant responses to certain tobacco smoke constituents had been reported. ${ }^{106,107}$ These effects were reverted by the treatment with a TRPM8 antagonist. Besides, the stimulation of TRPM8 channels can be harmful in patients with asthma and also with chronic obstructive pulmonary disease (COPD). In fact, cold-induced airway hyperresponsiveness can either induce asthma or exacerbate COPD and asthma, increasing morbidity. Cold-air inhalation causes airway constriction and can induce asthma associated with, for instance, winter sports. ${ }^{107,} 108$ These observations suggest the implication of TRPM8 channels both in physiological and pathological respiratory processes.

TRPM8 channels are also implicated, together with other TRPs (mainly TRPV1), in bladder sensation, showing a high interest as therapeutic targets for lower urinary tract dysfunction (LUTd). ${ }^{109}$ Several studies suggest the relevant role of TRPM8 in disorders like bladder pain syndrome and bladder hyperactivity. ${ }^{109,} 110$ The observation of upregulation of TRPM8 in bladder tissues of patients with painful bladder syndrome or idiopathic detrusor overactivity (IDO), in comparison to healthy controls, points in this direction, but the correlation of TRPM8 expression and these abnormalities still remain unclear. $^{111}$

Concerning obesity, there are two types of adipose tissue in mammals, the white (WAT) and the brown (BAT). The BAT is in charge of energy expenditure through the activation of the UCP1 protein, inducing thermogenesis, which can prevent the development of obesity. The work reported by Ma et al. showed that menthol promotes the overexpression of UCP1 in cultured brown adipocytes from wild-type mice, but not 
in TRPM8-deficient mice. ${ }^{112}$ Recent work reported by Rossato et al. ${ }^{113}$ showed that menthol or icilin activation of TRPM8 in WAT enhanced the UCP1 expression, having as a consequence an increase in glucose uptake and heat-production. The authors interpret these results as an induction of the brown phenotype in white adipocytes, which points to TRPM8 as a potential target for the treatment of obesity. ${ }^{113}$ Moreover, certain connection between TRPM8 gene polymorphisms and obesity-related metabolic syndrome has also been established. ${ }^{114}$

The presence of TRPM8 has also been detected in blood vessels, being the most abundant among the TRP channels in these tissues. ${ }^{115,116}$ TRPM8 expression has been observed in several rat arteries, and its activation by menthol or icilin promoted vasodilation. This vasodilation, induced by systemic administration of menthol, may be responsible for the fall in arterial blood pressure observed in an in vivo study in rabbits and cats. It has also been reported that the vasoconstriction or vasodilation depends on the previous vasomotor tone, and that it is mainly mediated by TRPM8 activation on smooth muscle cells. ${ }^{17}$ Although results of other research in this area are in agreement with these observations, ${ }^{117-119}$ further research is still required to confirm the real mediation of TRPM8 in vasodilation-related processes.

Experimental studies from the group of Belmonte and co-workers showed that reduction of temperature and subtle osmolality increases can stimulate DRG and TG neurons expressing cold-sensitive TRPM8 channels, which act as regulators of surface wetness of exposed body mucosae, like the eye. ${ }^{120,121}$ Therefore, another function of the TRPM8-expressing neurons is to act as regulators of ocular wetness through the modulation of the blink rate, thus predicting new opportunities for the understanding and treatment of dry eye, a common ophthalmological disorder that increased with age. 


\section{TRPM8 AGONIST CHEMOTYPES}

\subsection{Menthol and derivatives.}

Chemical modification of endogenous ligands or natural products, capable of interfering with a given receptor, is a widely used strategy in medicinal chemistry programs. ${ }^{122,123}$ Therefore, not surprisingly, the exploration of menthol-derived compounds emerged shortly after the discovery that menthol activates TRPM8 channels, ${ }^{45}$ with ester derivatives like Frescolat ML, ${ }^{124}$ carboxamide analogues such as $\mathbf{1}$ (WS-12, Figure $2),{ }^{125}$ described as the first high-affinity TRPM8 ligand, ${ }^{125}$ and fluorinated analogues claimed as the basis for diagnostic agents. ${ }^{126,127}$ Sherkheli et al. also quantified the activation of TRPM8 channel by several menthol carboxamide derivatives, some of which were initially prepared by Wei, E.T. et al. and others, finding up to 10-fold lower $\mathrm{EC}_{50}$ values than for the parent menthol. ${ }^{128}$ It seems that the cyclohexyl ring, characteristic of menthol, is behind the enhanced selectivity of the most representative derivatives in this series, $\mathbf{1}, \mathbf{2}$ (WS-5), ${ }^{128}$ and $\mathbf{3}$ (CPS-125) ${ }^{128}$ (Figure 2), when compared to lower homologues and linear analogues. 
<smiles>CC1CCC(C(C)C)C(O)C1</smiles>

Menthol $\mathrm{EC}_{50}: 60-200 \mu \mathrm{M}$<smiles>COc1ccc(NC(=O)C2CC(C)CCC2C(C)C)cc1</smiles>

1<smiles>[14CH][14C][Mg]</smiles><smiles>CC1CCC(C(C)C)C(C(=O)Nc2ccc(S(N)(=O)=O)cc2)C1</smiles>

3 $\mathrm{EC}_{50}: 30 \mu \mathrm{M}$<smiles>CC1CC[C@H](C(C)C)C(OC(=O)C(C)O)C1</smiles>

Frescolat ML $\mathrm{EC}_{50}: 160 \mu \mathrm{M}$<smiles>CCOC(=O)NC(=O)[C@@H]1CC(C)CC[C@H]1C(C)C</smiles>

2 $\mathrm{EC}_{50}: 26 \mu \mathrm{M}$

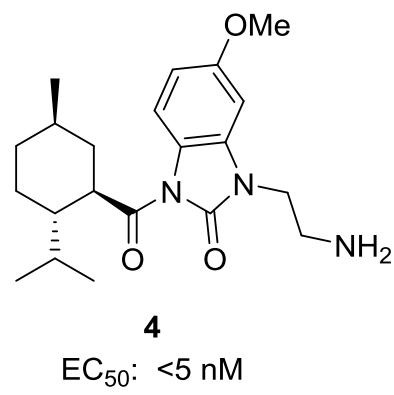

7 $\mathrm{EC}_{50}: 10 \mathrm{nM}$

Figure 2. Menthol and derived TRPM8 agonists

Dendreon Coorporation described related derivatives in several patents. Their mentholderived small-molecules, illustrated by compounds 4-6, are able to activate TRPM8 with nanomolar potency. ${ }^{129,130}$ In this family of compounds, the substituted cyclohexyl moiety and the free amino groups seem desirable structural requirements for good 
agonist activity, while the carboxamide substituent accepts bezimidazolone (D3263, 4), phenyl (5) and substituted ethyl (6) derivatives. In addition of increasing $\mathrm{Ca}^{2+}$ entry in CHO cells expressing TRPM8, selected compounds from this series prove to stimulate cancer cell apoptosis, and substantially reduce xenograft tumors in animal models of human prostate cancer, without showing apparent toxicity. Compound $\mathbf{4}$ from this series, showing good oral bioavailability, entered Phase I clinical trials in 2009 for the assessment of safety, determination of the maximum tolerated dose, and characterization of the pharmacokinetic profile after a single dose and repeated daily dosing (NCT00839631). In men with advanced prostate cancer, preliminary results indicated that this compound is able to stabilize the disease. Apart from elevations in Troponin-T, no signs of cardiac toxicity were observed (Maximun tolerated dose: 100 mg/day). ${ }^{131}$ Last updated data at ClinicalTrials.gov was April 30 ${ }^{\text {th }}$, 2012. Some preclinical data also demonstrated the potential of $\mathbf{4}$ to treat benign prostatic hyperplasia by itself or in combination with the synthetic $5 \alpha$-reductase inhibitor finasteride (additive effect)

Some diastereomeric menthol ethers, like 7, have been described in a recent Japanese patent to display nanomolar activation of the TRPM8 receptors. ${ }^{132}$ Menthol-related cyclohexane-hydantoin spirocyclic derivatives, as well as pyrazolyl-5-one and pyrimidinetrione analogues, have also been claimed as TRPM8 effectors (structures not disclosed). ${ }^{133}$

Despite numerous studies on its applications in cosmetics, which are not being commented here, there are several clinical trials evaluating the usefulness of menthol alone or in combination with other active principles as a therapeutic agent. A few of these studies are recorded here, including their ClinicalTrials.gov identifier number. Thus, menthol alone or Biofreeze ${ }^{\circledR}$, a topical lotion containing menthol and alcamphor, 
is being examined for treating pain symptoms in slaughterhouse workers with symptoms of Carpal Tunnel Syndrome (NCT01716767), as a topical counter-irritant on cutaneous pain and hyperalgesia provoked by topical application of TRPA1-agonists (NCT02653703), to alleviate shoulder pain (NCT01827306), musculoskeletal disorders associated to neck pain (NCT01542827), and persistent neuropathic pain from chemotherapy among breast and colorectal cancer patients (NCT01855607).

An invention by researchers at the Edinburgh University also claims that activation of TRPM8 channels induces analgesia in chronic neuropatic pain states. ${ }^{134}$ Therefore, activation agents including menthol and menthyl derivatives, among others, could be useful for the treatment of diseases and conditions which involve neuropathic pain, such as that induced by trauma, demyelination, cancer or inflammatory states, phantom-limb, back and bone pain, and chemotherapy neuropathy.

As a potential alternative for the prevention and treatment of hypertension, the Third Military Medical University is evaluating the effects of menthol on blood pressure in hypertensive patients (a double-blind phase II clinical study, NCT01408446).

Studies performed with two different human melanoma cell lines expressing TRPM8, reported the dose-dependent in vitro cytotoxic effects of menthol. ${ }^{29,}{ }^{135}$ Chanchao and coworkers had in fact stated an effectiveness comparable with that of 5-FU, with the advantage that menthol has no toxicity, while the side-effects of 5-FU are multiple and non-negligible. ${ }^{135}$ Menthol also showed a significant decrease on the viability of a bladder cell line T24, inducing cell death through TRPM8 activation. ${ }^{136}$

Inventors from the Miguel Hernández University have patented that the TRPM8 receptor is linked to the control of lacrimation, and that its activation with agonists, like menthol, increased tearing, thus leading to a promising remedial for the dry eye condition. ${ }^{137}$ As agonists they studied menthol, frescolat, geraniol, eucaliptol, icilin and 
other cooling agents. The invention also relates the use of TRPM8 antagonists as useful treatment for epiphora (excessive tear production).

The activity and interest of various natural and synthetic menthol derivatives, along with other cooling compounds that behave as activators of thermoTRPM8, have been compiled in a 2012 comprehensive review. ${ }^{138}$

\subsection{Pyrimidine derivatives.}

Icilin is a synthetic compound that behaves as an agonist of TRPM8 (about 200-fold more potent than menthol), ${ }^{26,139}$ but also suppressed TRPM8 current activation by other agonists, ${ }^{22}$ and modulates TRPV $3,{ }^{140}$ and TRPA $1 .{ }^{22}$ Therefore, icilin has been and continues being used as a pharmacological tool for studying TRP channels. ${ }^{141-143}$ Icilin has anti-inflammatory activity, ${ }^{55}$ has been claimed for the treatment of different neurological disorders, as menthol and linalool, ${ }^{144}$ and reduces the activity and expression levels of E2F1, ${ }^{145}$ a transcription factor controlling the cell cycle in prostate cancer cells. The group of De Petrocellis explored the preparation of new analogues by modification of the pyrimidin-2-one central scaffold of icilin, in an attempt to improve the therapeutic potential. ${ }^{146}$ Work at the three rings of the icilin molecule demonstrated very narrow limits for modification. SAR studies point to the importance of the presence and position of the $o-\mathrm{OH}$ and $m-\mathrm{NO}_{2}$ substituents on the distal phenyl groups. The phenyl ring at 1-position of the pyrimidine central scaffold tolerates some variations, like the addition of a methyl group in relative para position to the $\mathrm{OH}$ or the presence of $\mathrm{m}$-halogens $(\mathrm{I}<\mathrm{Br}>\mathrm{Cl}$ ) in non-OH analogues, but always provided less potent compounds. Either a lower homologue of the central ring or conformationally restricted tricyclic derivatives were totally inactive. ${ }^{146}$ 


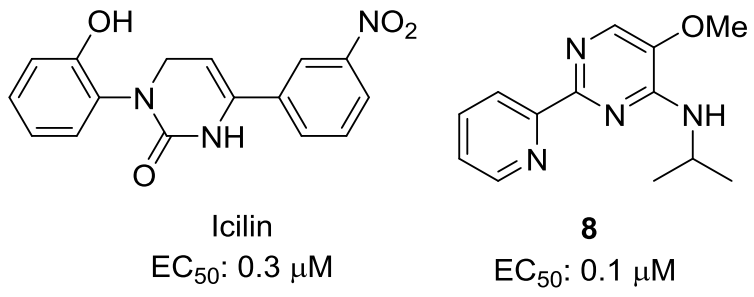

Figure 3. Pyrimidine-derived TRPM8 agonists

Structurally unrelated pyrimidine derivatives, exemplified by compound $\mathbf{8}$, produce cooling effects on skin and mucous membranes through the interaction with the TRPM 8 receptor (submicromolar potencies). ${ }^{147}$

\subsection{Five-membered heterocycle derivatives}

In a recent paper by $\mathrm{R}$. Patel and coworkers, compound 9 (M8-Ag), with a 1,2,4-triazole central scaffold, was described to display more potent anti-hyperalgesic effects than menthol in a rat model of neuropathic pain. ${ }^{66}$ This compound activates TRPM8 channels with a $45 \mathrm{nM} \mathrm{EC}$ E0 $_{50}$ value and also TRPA1 thermoreceptors, although with lower potency $(4 \mu \mathrm{M})$. It attenuates neuronal responses after innocuous and noxious cooling, and reverses hypersensitivity to acetone-induced cooling in spinal nerve-ligated (SNL) rats. Results from this study led the authors to suggest that TRPM8 agonists might be beneficial in neuropathy without affecting normal cold sensation.

The group of Ostacolo described the preparation of a family of isoxazole derivatives and their preliminary characterization as TRPM8 agonists. ${ }^{148}$ From the 12 isoxazole collection, some compounds were more potent than menthol (up to 200-fold), but most of them display lower efficacy. A few compounds, like 10, elicit stronger allodynic responses than menthol in rats with chronic constriction injury of the sciatic nerve. 


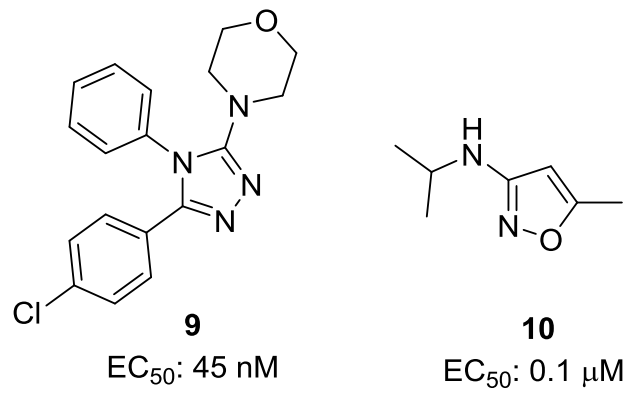

Figure 4. 1,2,4-Triazolyl- and isoxazolyl-derived TRPM8 agonists

\subsection{Other TRPM8 agonists}

Different plant-derived natural products have been identified as TRPM8 agonists, including eugenol, ${ }^{12}$ eucalyptol, ${ }^{124}$ geraniol, ${ }^{124}$ and neferine, ${ }^{149}$ all of them displaying moderate to low potency ranging from $\mu \mathrm{M}$ to $\mathrm{mM} \mathrm{EC}_{50}$ values (Figure 5). The activation/sensitization to cold of mammalian TRPM8 seems to be responsible for the enhancement of innocuous cold and noxious cold sensations induced by camphor, which also potentiate heat sensations through activation of TRPV1 and TRPV3 channels. ${ }^{150}$

5-Methyl-2-(1-pyrrolidinyl)-2-cyclopenten-1-one (11), isolated from roasted malt, ${ }^{151}$ and some hybrid derivatives, ${ }^{152}$ were identified as intense cooling compounds. Although authors mentioned TRPM8 channels as cold-sensitive receptors, no data is provided regarding the direct action of these compounds on the mentioned thermoreceptor.

In patch-clamp experiments, eucalyptol, from eucalyptus oil, evokes inward currents in TRPM8-expressing cell, and also behaves as a TRPA1 antagonist, while its regioisomer 1,4-cineole activates both receptor types. ${ }^{153}$ Studying different small-molecules BASF SE identified new chemotypes able to activate TRPM8 channels. ${ }^{147,154}$ Thus, a series of tetrahydrofuro[3',4':5,6]pyrido[2,1-a]isoquinoline-dione derivatives, exemplified by compound 12, and different secondary caffeic-derived amides, like derivative 13, show submicromolar potencies (Figure 5). 
Wei described in a recent patent a series of new di-isopropyl-phosphinoyl alkene (DIPA) compounds for the topical treatment of sensory discomfort (itch, dermatitis, psoriasis, and ocular discomfort, among others). ${ }^{155}$ In this series, the ${ }^{i} \operatorname{Pr}$ group is preferred over sec- or iso-butyl homologues, and optimal length for the linear aliphatic alkene is 6 to 9 carbon atoms. These compounds elicit submicromolar $\mathrm{EC}_{50}$ values and $>5$-fold increased potency compared to menthol (i.e., 14, Figure 5). A related phosphine oxide, containing sec-butyl substituents instead of iPr, was previously studied, showing a dose-dependent and reversible activation of TRPM8 with an $\mathrm{EC}_{50}$ value of $4.1 \mu \mathrm{M} .{ }^{156}$ While studying a series of $N$-Aryl and $N$-benzyl triptamine derivatives to explore the structural requirements determining TRPM8 modulation, Bertamino and co-workers described a new compound able to activate the channels under investigation (15, Figure 5). ${ }^{157}$ Thus, triptamine derivative 15 displays significantly higher potency $\left(\mathrm{EC}_{50}=40\right.$ $\mu \mathrm{M})$ than menthol, and a similar efficacy under patch-clamp experiments. 
<smiles>C=CCc1ccc(O)c(OC)c1</smiles>

Eugenol

$\mathrm{EC}_{50}: 66 \mu \mathrm{M}$<smiles>CC(C)=CCC/C(C)=C/CO</smiles>

Geraniol $\mathrm{EC}_{50}: 6 \mathrm{mM}$<smiles>CC12CCC(CC1=O)C2(C)C</smiles>

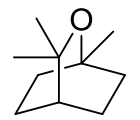

Eucalyptol

$\mathrm{EC}_{50}: 7 \mathrm{mM}$<smiles>COc1ccc(C[C@H]2c3cc(Oc4cc(C[C@@H]5c6cc(OC)c(OC)cc6CCN5C)ccc4O)c(OC)cc3CCN2C)cc1</smiles>

Neferine

Camphor<smiles>CC1CC=C(N2CCCC2)C1=O</smiles>

11<smiles>CC1OC(=O)C2=C1N1CCc3ccccc3C1CC21SCCS1</smiles>

12

$\mathrm{EC}_{50}: 0.4 \mu \mathrm{M}$

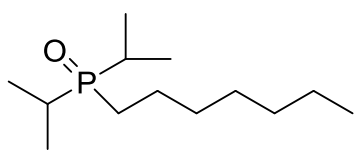

14

$\mathrm{EC}_{50}: 0.7 \mu \mathrm{M}$<smiles>COc1ccc(/C=C/C(=O)N(C2CCCCC2)C2CCCCC2)cc1</smiles>

13

$\mathrm{EC}_{50}: 0.1 \mu \mathrm{M}$

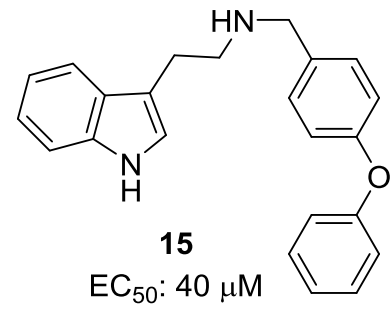

Figure 5. Natural products and other TRPM8 agonists.

\section{TRPM8 ANTAGONIST CHEMOTYPES}

During the last decade, several pharmaceutical companies and a few academic groups have made enormous efforts in the search for new antagonists of the TRPM8 channel. The different families of compounds described to date are recorded in this section, with 
an intended rational classification, based first on the central structural scaffold and then, if necessary, subcategorizing them by other secondary motifs.

\subsection{N-Heteroaryl-N-benzyl sulfonamides.}

6.1.1. Benzothiophene derivatives. Several patents from Janssen claimed the interest of a big family of benzothiophene-bearing N-benzyl sulfonamides (examples 16-20), and related N,N'-disubstituted analogues (21), as potent TRPM8 antagonists (Figure 6). A first patent describes 850 benzo[b]thiophene derivatives and some aza-analogues through the combination of different substituents at position 3 of the bicyclic skeleton, at the N-benzyl susbstituent and at the sulfonyl moiety. ${ }^{158}$ Preliminary HTS evaluation was performed in an in vitro canine TRPM8 functional assay, measuring the changes produced by compounds in the intracellular $\mathrm{Ca}^{2+}$ concentration induced by the agonist (menthol or icilin). From the results of this assay, it can be said that chlorine, bromine, or small alkyl groups are preferred at position 3 , while at the benzyl moiety a $m$ - or $p$ fluorine or trifluoromethyl group, or a combination of them, favored TRPM8 antagonist properties. Either alkyl or aryl groups at the sulfonyl moiety are well tolerated. The antagonist properties for the most promising compounds were confirmed through patch clamp experiments. Thus, representative compound $\mathbf{1 6}$ exhibits high potency either in the hTRPM8 HTS assay $\left(\mathrm{IC}_{50}: 4 \mathrm{nM}\right)$ or in patch clamp experiments $\left(\mathrm{IC}_{50}: 1.1 \mathrm{nM}\right.$ and $2.3 \mathrm{nM}$, after menthol and cold activation, respectively). The potent TRPM8 antagonist properties were confirmed in different animal models: by reversing carrageenaninduced heat hypersensitivity (64\% at $30 \mathrm{mg} / \mathrm{Kg}$, p.o.) and CFA-induced thermal and mechanical hyperalgesia (91\% at $10 \mathrm{mg} / \mathrm{Kg}$, p.o.). This compound was also able to reduce icilin-stimulated "wet-dog" shakes (WDS) in rats with an $\mathrm{ED}_{50}$ of $2.5 \mathrm{mg} / \mathrm{Kg}$, cold-evoked cardiovascular pressor responses (75\% of inhibition), and acetone-induced hypersensitivity, an in vivo model of neuropathic pain $(69 \%$ pain relief, $30 \mathrm{mg} / \mathrm{Kg}$, 
p.o.). A ${ }^{18} \mathrm{~F}$ labeled analogue of $\mathbf{1 6}$, its related derivative $\mathbf{1 7}$ and the ${ }^{11} \mathrm{C}$ labeled compound 18 were also protected as useful tools for the labeling and imaging of TRPM8 channels. ${ }^{159}$ One year later of the initial patent in this series, Janssen published an extension that covered potent aminoethylsulfonyl derivatives, like 19, and some less active naphthalene analogues. ${ }^{160}$ Closely related sulfamides, exemplified by compound 20 in Figure 6, also afforded TRPM8 antagonists with nanomolar potencies in the HTS assay, although their efficacy in animal models was not revealed.$^{161}$

At the beginning of 2012, Janssen published the US patent 0053347 describing a new series of benzothiophene derivatives, resembling to some extent previous series in this section, but bearing a phosphonate moiety instead of the initial sulfonamide. ${ }^{162}$ The 3 bromothiophene 21, with a $9 \mathrm{nM} \mathrm{IC}_{50}$ value in the HTS functional assay and good antagonist in vivo activities, is one of the most active compounds in this series. Thus, this compound reverses up to $80 \%$ the icilin-induced behaviors in rats $(30 \mathrm{mg} / \mathrm{Kg}$, p.o.), and several compounds within this family are also active in the CFA-induced model of hyperalgesia ( $\mathrm{ED}_{50}$ up to $5.2 \mathrm{mg} / \mathrm{Kg}$ ). As it could be expected, the configuration of the asymmetric center of $\mathbf{2 1}$ is important for the antagonistic activity, with its $R$-enantiomer and the racemic form showing one-order of magnitude lower potencies. An initial SAR study, including a part of the compounds covered by the patent, has been published, and highlights the preference for small alkyl groups at position 3 of the benzothiophene ring, and either ethyl or isopropyl esters alongside the phosphonate. ${ }^{163}$ 

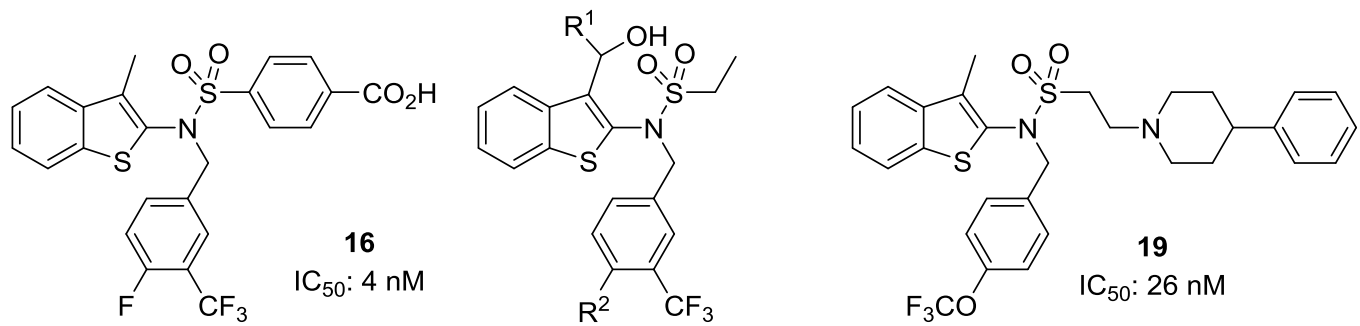

17: $R^{1}=M e, R^{2}={ }^{18} F$

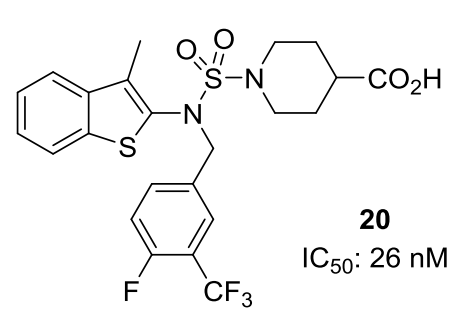

18: $R^{1}={ }^{11} \mathrm{Me}, \mathrm{R}^{2}=\mathrm{F}$

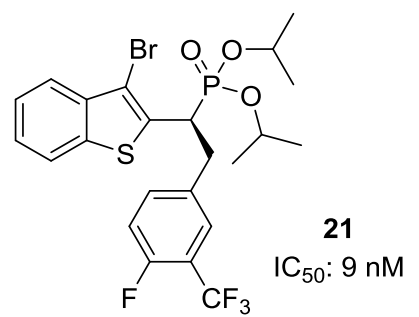

Figure 6. TRPM 8 antagonists: Compilation of representative $N$-benzothiophene sulfonamides and related compounds

6.1.2. Benzimidazole derivatives. A second family of TRPM 8 antagonists with a central N-sulfonamide motif includes compounds substituted with a benzimidazole moiety (examples 22, 23, Figure 7). A couple of patents protect the TRPM8 antagonist activity of the mixtures of 1,3- and 1,2-N-disubstituted derivatives, initially obtained after benzylation of the corresponding 1-monosubstituted analogues. ${ }^{164,}{ }^{165}$ In these series, low alkyl groups at the N1 atom are well tolerated (ethyl preferred), and one or two fluorine atoms or a $\mathrm{CF} 3$, or a combination of both, at the phenyl ring of the benzyl moiety increase potencies with respect to unsubstituted analogues, as it was also found for the incorporation of $\mathrm{F}$ or $\mathrm{CF} 3$ at position 5 of the benzimidazole nucleus.

In general, the best compounds within these collections were less potent than 2-alkene substituted benzimidazole related derivatives, which displayed nanomolar potency in the canine hTRPM8 $\mathrm{Ca}^{2+}$-flux assay. ${ }^{166}$ A representative compound in this new series, 24, is able to reverse cold hypersensitivity in a model of neuropathic pain (oral 10 $\mathrm{mg} / \mathrm{Kg}, 91 \%$ ), and icilin-induced WDS (oral $30 \mathrm{mg} / \mathrm{Kg}, 98 \%$ ), even if it does not show optimal PK properties regarding metabolism. ${ }^{167}$ 
Analogues of $\mathbf{2 4}$ bearing spiroheterocyclic systems in position 2 of the central skeleton provided highly potent TRPM8 antagonists, with $\mathrm{IC}_{50}$ values in the subnanomolar range. ${ }^{168}$ In this series, the dihydro isoxazole ring is preferred over the oxazole and imidazole at the spiro moiety. Compound 25 inhibits cold-stimulated currents in HEK cells expressing hTRPM8, reverses icilin-induced behaviors in rats $(98 \%, 10 \mathrm{mg} / \mathrm{Kg}$, p.o.), and reduces neuropathic pain (acetone-mediated hypersensitivity, 83\%). This compound exhibits a good pharmacokinetic profile, with excellent oral bioavailability and relatively high metabolic stability. ${ }^{57}$

Related azabenzimidazole derivatives, substituted with different pentaheterocycles at position 2 , here represented by compound 26, are also patented. ${ }^{169}$ Chlorine, alkyloxy and substituted amines are the groups of choice at 7-position, while pyrazole ring provided the most potent compounds among all the 2-pentaheterocycles incorporated in this series.
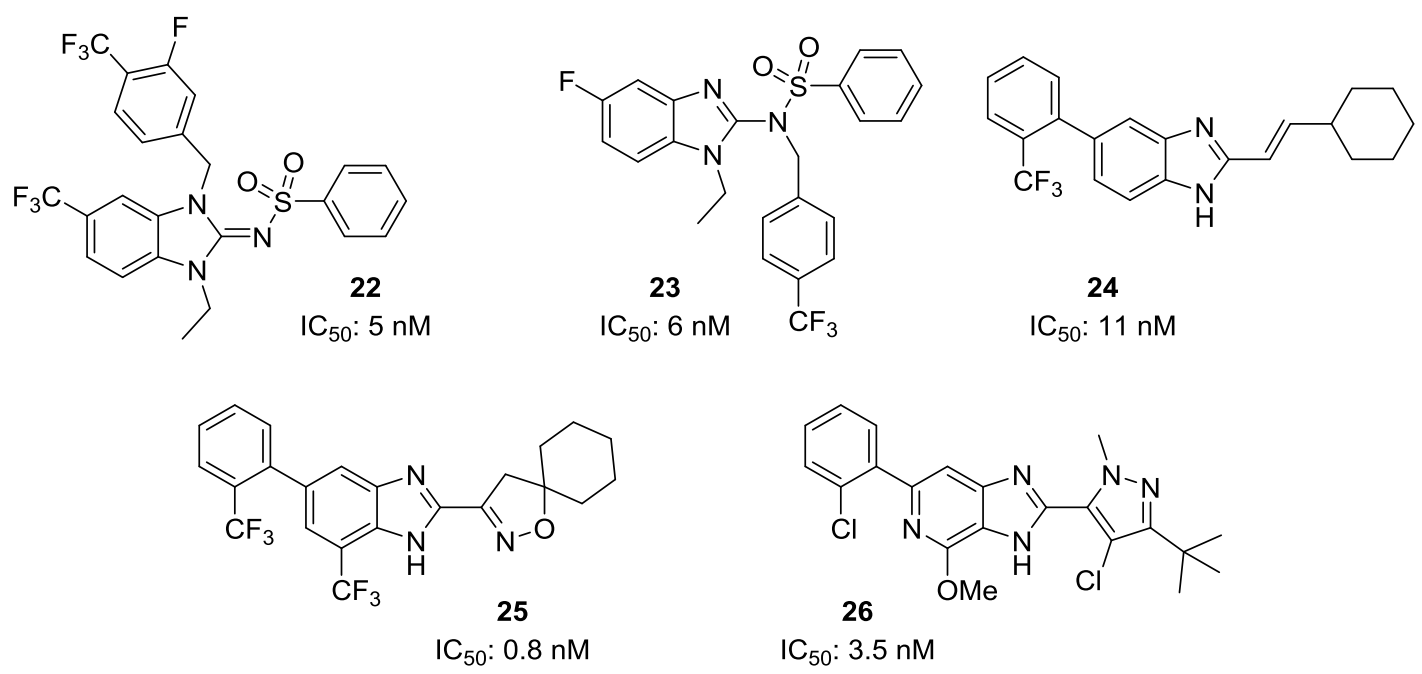

Figure 7. TRPM 8 antagonists: Representative $N$-benzimidazole sulfonamides and related compounds.

6.1.3. Pyridine derivatives. Two patents on $N$-benzyl- $N$-pyridylsulfonamide structures, similar to those described in the previous sections, have been disclosed by RaQualia 
Pharma. ${ }^{170,} 171$ In a first series of 199 compounds, exemplified by the N-pyridine derivative 27 (RQ00203078, Figure 8), ${ }^{170}$ the observed activities indicated the need for a 3-Cl atom on the pyridine ring, combined with $\mathrm{CF}_{3}, \mathrm{CH}_{3}$ or $\mathrm{Cl}$ groups at position 5. In addition, the incorporation of different substituents at the phenyl ring of the benzyl moiety either maintain or improve the activity, as it does the change of the carboxylic acid by a hydroxymethyl group or differently substituted carboxamides. In the second set of compounds, the phenyl ring of the benzyl substituent has successfully been replaced by diverse heterobicycles, like benzofuran, indole, indazole, and benzotriazole derivatives. In these patents, the inventors claimed for good in vitro antagonist properties in HEK293 and human malignant melanoma cell lines, and also indicated potent activities in different in vivo models, although there is no disclosed data about that. They also claim for beneficial effects of their compounds on neuropathic pain of cold- and static-allodynia, icilin-caused WDS, oxaliplatin-induced pain, and overactive bladder in rats suffering from cystitis. A recent paper by this group describes that compound 27 attenuates the shaking behavior with an $\mathrm{ED}_{50}$ of $0.65 \mathrm{mg} / \mathrm{kg}$ (p.o.), indicating that this sulfonamide derivative is a potent and orally active TRPM8 antagonist. This compound, which is commercially available as a pharmacological tool, is also selective over other TRP channels (A1, V1, V4) and has been selected as an advanced compound for further investigation. ${ }^{172}$

Related analogues having a condensed pyridine moiety (isoquinoline) have been patented by Mitsubishi Tanabe Pharma Corporation (see compound 28 in Fig. 8). ${ }^{173}$ Among these very potent compounds, the presence of the cyclopropyl group is an important structural requirement, while the tetrazole group (a carboxylic acid isostere) can be substituted by other nitrogen-containing heterocycles, like tetrazolone, 1,2,4triazole and 1,2,4-oxadiazole-5-one, and even by $\mathrm{CO}_{2} \mathrm{H}, \mathrm{CO}_{2} \mathrm{Me}$ and $\mathrm{CN}$ groups without 
significant loss of antagonist activity. Similarly, different groups are allowed at orthoposition of the tetrazole moiety, with $\mathrm{Me}, \mathrm{OMe}, \mathrm{Cl}$ and $\mathrm{NMe}_{2}$ within the preferred ones.<smiles>O=C(O)c1ccc(S(=O)(=O)N(Cc2ccc(OC(F)(F)F)cc2)c2ncc(C(F)(F)F)cc2Cl)cc1</smiles><smiles>O=S(=O)(c1ccc(-c2nnn[nH]2)cc1)N(Cc1ccc(OC(F)(F)F)cc1)c1ncc2ccccc2c1C1CC1</smiles><smiles>COc1cc(CN(CCN)c2nc3ccccc3s2)ccc1OCc1ccccc1F</smiles>

Figure 8. TRPM8 antagonists: Representative pyridine-derived $N$-Heteroaryl sulfonamides and related compounds.

In 2010, Glenmark patented a new family of compounds, which keeps an N-heteroaryl (benzothiazole or benzoxazole) and an N-benzyl moiety on a nitrogen atom, but differs from previous series in the third N-substituent. ${ }^{174}$ Instead of the sulfonyl appendage, these tertiary amines bear an alkylamino moiety, as illustrated by compound 29 . In this series, unsubstituted benzo[d]thiazol-2-yl and benzo[d]oxazol-2-yl led to potent derivatives, and some aza analogues are acceptable. The presence of $F$ atoms $(2-$ or 2,4) or a 2-methyl group in the benzyloxy moiety is coupled to high activity, as the $m$-OMe group on the N-benzyl substituent. 


\subsection{Urea derivatives.}

The (3-chloro-pyridin-2-yl)-piperazine derived urea (BCTC, 38) has been one of the first TRPM8 antagonists used for studying the pharmacology of this channel $\left(\mathrm{IC}_{50}: 0.8\right.$ $\mu \mathrm{M}$, Figure 9). ${ }^{124}$ This compound, which is commercially available, was initially prepared as a TRPV1 modulator $\left(\mathrm{IC}_{50}: 35 \mathrm{nM}\right)$, therefore is a non-selective TRPM8 antagonist. Probably, in the search for more potent and selective TRPM8 antagonists, this compound inspired the design and synthesis of other urea derivatives as those described in the two following subsections.

6.2.1. Tetrahydroisoquinolines and aza-analogues. In 2009, Amgen Inc. published two patents describing tetrahydroisoquinolines and aza-analogues as TRPM8 antagonists, and claimed their potential value for the treatment of diverse pathologic conditions. ${ }^{175 \text {, }}$

${ }^{176}$ In their efforts to validate TRPM8 channel as a novel target for pain, they discovered a tetrahydrothienopyridine derivative after a high-throughput screening campaign. The initial hit was then modified to lead to tetrahydroisoquinoline-urea analogues with higher potency and increased metabolic stability. ${ }^{177}$ In this series, modification at the Nphenyl ring is restricted to the incorporation of $\mathrm{F}$ atoms or its replacement by unsubstituted pyridine rings. Although with suboptimal pharmacokinetic properties, compound 31 (Figure 9) reduces icilin-induced WDS in a dose dependent manner (80\%, $30 \mathrm{mg} / \mathrm{Kg}$, po). Further optimization of potency and pharmacokinetic properties afforded analogues $\mathbf{3 2}$ and $\mathbf{3 3}$, with hTRPM8 $\mathrm{IC}_{50}$ values of 10 and $12 \mathrm{nM}$, respectively, and balanced properties that made them ideal for in vivo evaluation. ${ }^{178}$ In the icilin induced rat-wetdog shakes (WDS) model, compound 32 achieves maximal inhibition at $10 \mathrm{mg} / \mathrm{kg}$ (p.o.), while 33 results in $68 \%$ inhibition of WDS at $1 \mathrm{mg} / \mathrm{kg}$, and the icilin effect was completely blocked at $3 \mathrm{mg} / \mathrm{kg}$. Compared to the initial hit $\mathbf{3 1}$, the higher in 
vivo activity of $\mathbf{3 3}$ was attributed to the increased drug plasma levels, which results from the improved pharmacokinetic properties of the latter molecule. This compound was selected for further progression in preclinical models of pain.

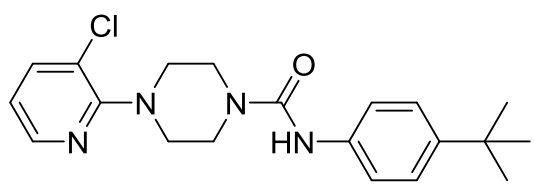

30 (BCTC)

$\mathrm{IC}_{50}: 0.8 \mu \mathrm{M}$

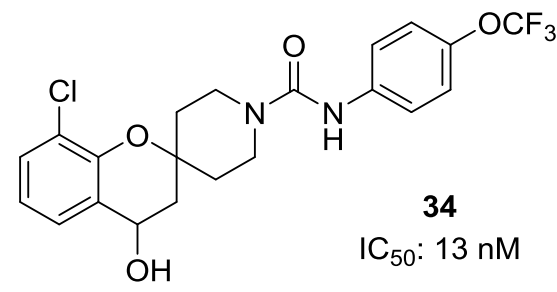

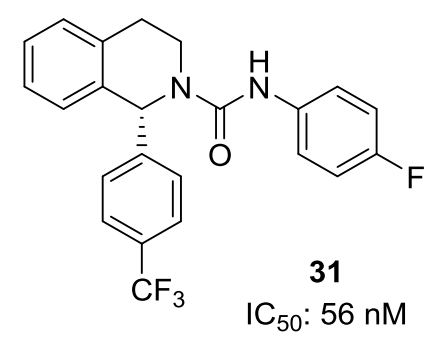

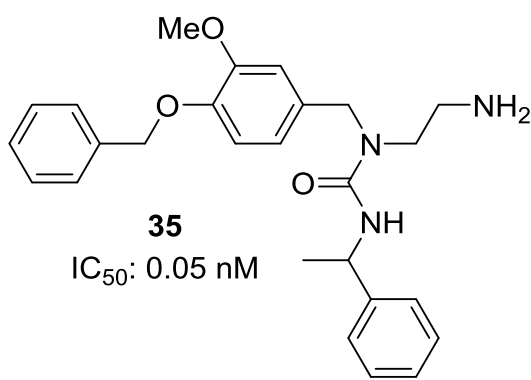

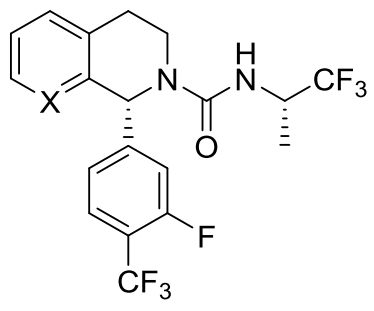

32: $\mathrm{X}=\mathrm{CH} ; \mathrm{IC}_{50}: 10 \mathrm{nM}$ 33: $X=N ; I C_{50}: 12 \mathrm{nM}$

Figure 9. TRPM8 antagonists: Representative urea derivatives.

6.2.2. Spiro[chromene-2,4'-piperidine] derivatives. Following an analogue-based rational design, synthesis and screening, Glenmark Pharmaceuticals discovered a set of spiro[chromene-2,4'-piperidine]phenylureas that behave as TRPM8 antagonists (see derivative $\mathbf{3 4}$ in figure 9). ${ }^{179,} 180$ Selected compound 34 shows nanomolar in vitro TRPM8 potency, moderate to high metabolic stability in different species, and quantifiable levels in plasma up to $8 \mathrm{~h}$ post-dose following oral administration. The $R$ stereoisomer is more potent and more selective over other TRP channels than its optical $S$-antipode. In in vivo models of neuropathic pain, $\mathbf{3 4}$ is able to inhibit the acetoneinduced allodynia in rats $(74 \%, 10 \mathrm{mg} / \mathrm{Kg}$, p.o.), significantly reduced the icilin-induced WDS in mice (72\% efficacy, $30 \mathrm{mg} / \mathrm{Kg}$, p.o.), and produced a dose-dependent inhibition of paw licking after oxaliplatin injury (100\% effect, $30 \mathrm{mg} / \mathrm{Kg}$, p.o.). ${ }^{180}$

6.2.3. Other urea derivatives. Very potent TRPM8 antagonists, containing a central urea motif have been patented by Bayer. ${ }^{181}$ Compound $\mathbf{3 5}$ is one of the most potent TRPM 8 
antagonist described to date, displaying subnanomolar potency in the menthol-induced $\mathrm{Ca}^{2+}$ influx in TRPM8-expressing HEK293 cell assay (Figure 9).

\subsection{Phenylglycine derivatives.}

Another collection of TRPM8 antagonists is that of $\mathrm{N}$-arylphenylglycine amides, described by Janssen Pharmaceutica (i.e., 36, Figure 10). ${ }^{182,} 183$ This family comprises two libraries of 375 and 55 compounds, in which 2-arylpyrrolidine and isoquinoline substituents gave better activities than other mono- and bis-heterocyclic systems. Substituted phenyl and benzothiophene are preferred aryl moieties at the $\alpha$ position of the amino acid. As expected, the influence of the configuration was crucial for the activity of these Phg derivatives. Thus, compound $36(S, S)$ shows one-order of magnitude higher potency than its $(R, R)$ and $(R, S)$ isomers, while the $(S, R)$ diastereoisomer undergoes more than 100-fold drop in the antagonist activity, indicating a larger influence on the activity of the pyrrolidine stereogenic center than that of the Phg residue. Compound $\mathbf{3 6}$ demonstrated good in vivo efficacy reducing WSD in rats produced after administration of icilin. ${ }^{183}$

Related phenylglycine amides, combining either a differently substituted $\mathrm{N}-(R)$-inden-1yl ring or a 1-phenylethyl group with an $\mathrm{N}$-acyl moiety, bearing aryl- or heteroaryl

groups, have been recorded in two recent patents by Kissei Pharmaceutical. ${ }^{184,}$ 185 Preferred compounds from these series are able to reduce the icilin-evoked wet-dog shakes in rats (i.e., derivative $\mathbf{3 7}, 100 \%$ inhibition at $3 \mathrm{mg} / \mathrm{Kg}$ ). These compounds also elongate significantly the micturition interval in guinea pigs (up to $221 \%$ at 0.5 $\mathrm{mg} / \mathrm{Kg} / \mathrm{mL}$ ). 

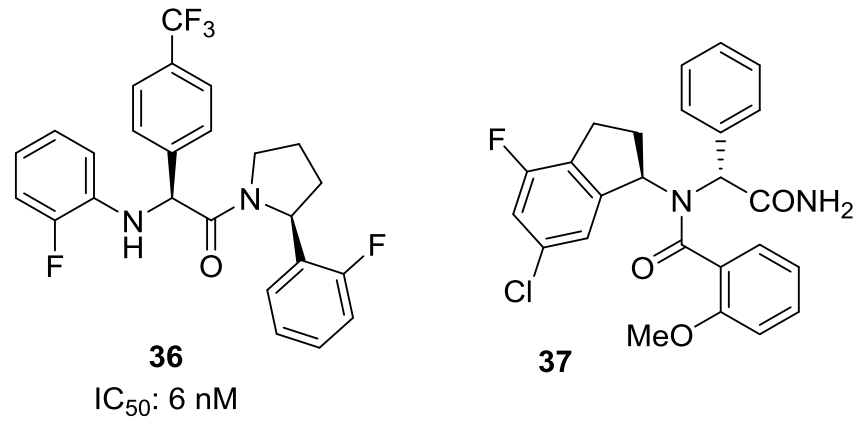

Figure 10. TRPM8 antagonists: Illustrative phenylglycine derivatives.

\subsection{Tryptamine derivatives.}

The structural requirements behind TRPM8 modulation were also explored by means of a series of $\mathrm{N}$-substituted tryptamines. Apart from the already mentioned agonist $\mathbf{1 5}$, most derivatives within this series behave as TRPM8 antagonists, with the (N,Ndibenzyl-2-(1H-indol-3-yl)ethanamine (38) as the most potent inhibitor of calcium influx in HEK293 cells. ${ }^{157}$ Perfusion of tryptamine derivative $38(3 \mu \mathrm{M})$ produced a complete inhibition of menthol-induced TRPM8 currents measured at $+80 \mathrm{mV}$, with kinetics slower than that observed for 30 (BCTC), but increased potency $\left(\mathbf{3 8}, \mathrm{IC}_{50}=367\right.$ $\mathrm{nM})$.

5-Substituted tryptamine derivatives were also identified as antagonists of TRPM8 after screening of the Renovis corporate collection and further evaluation of commercial analogues. ${ }^{186}$ Compound 39, identified as the most potent tryptamine derivative within this family, lacks of selectivity since it is a known ligand of 5-HT receptors. ${ }^{187}$

Voacangine, a conformationally restricted tryptamine-derived natural product, competitively displaces menthol, but not icilin, from TRPM8 receptors $\left(\mathrm{IC}_{50}=9\right.$ $\mu \mathrm{M}){ }^{188}$ This compound is a stimulus-selective antagonist, because it did not abrogate cold-induced channel opening but inhibited chemical agonist-provoked TRPM8 activation. In addition, voacangine competitively inhibits capsaicin binding on TRPV1, 
and blocks capsaicin- and heat-induced activation of this thermoreceptor, and shows some TRPA1 agonist activity.

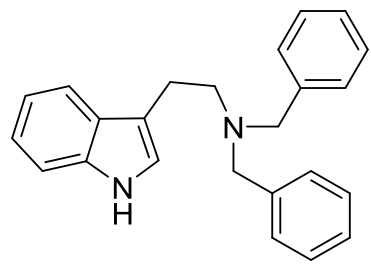

38

$\mathrm{IC}_{50}: 367 \mathrm{nM}$

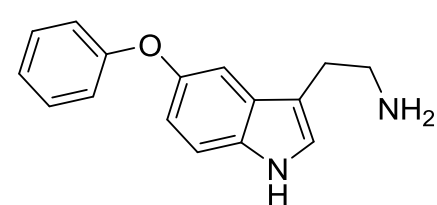

39

$\mathrm{IC}_{50}: 340 \mathrm{nM}$

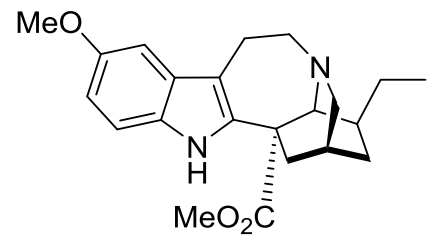

Voacangine $\mathrm{IC}_{50}: 9 \mu \mathrm{M}$

Figure 11. TRPM8 antagonists: Selected tryptamine derivatives.

\subsection{Tertiary amide derivatives.}

A collection of 177 2-benzyloxy-benzoic acid amide derivatives were protected under patent by Bayer Healthcare AG. ${ }^{189}$ The prototype N-(2-thienylmethyl) derivative $\left(\mathrm{AMTB}, 40, \mathrm{IC}_{50}=8 \mathrm{nM} \text {, Figure } 12\right)^{189}$ in this series was used as a pharmacological tool to learn that, in rats, this TRPM8 blocker attenuated bladder micturition reflex, without affecting the contraction amplitude, and reduced nociceptive reflex responses to noxious bladder distension. ${ }^{190}$

More recently, Pfizer and collaborators described new salicyl amide derivatives with improved properties. ${ }^{191}$ Thus, following a lead-hopping strategy on the closely related 40 (AMTB) analogue 41, they prepared three libraries with decreasing degree of similarity. Compound $\mathbf{4 2}$ from one of these libraries displays improved potency $\left(\mathrm{IC}_{50}=\right.$ $21 \mathrm{nM})$, and better lipophilic efficiency compared to $\mathbf{4 1}$.

The HTS screening of the Pfizer in house collection allowed the identification of another tertiary amide derivative with weak inhibitory properties of TRPM8 receptors, which upon optimization resulted in the quinolin-3-carboxamide derivative PF05105679 (43). ${ }^{192}$ Modifications at the acidic group resulted in reduced potency, while at the other benzylic residue only the incorporation of a $m$-chlorine atom is well 
tolerated. Its potency against TRPM8 was confirmed by patch-clamp electrophysiology studies, and selectivity was assessed through evaluation in a set of different receptors, enzymes and ion channels, including related thermoreceptors (TRPV1 and TRPA1) and hERG. In preclinical studies, compound $\mathbf{4 3}$ exhibited good oral absorption, moderate blood clearance and low toxicity. In humans, a single $900 \mathrm{mg}$ dose was effective in a cold pressor test (Phase I, NCT01393652), without significant changes in core body temperature, but intolerable hot sensation side effects precluded further progression into the clinic.

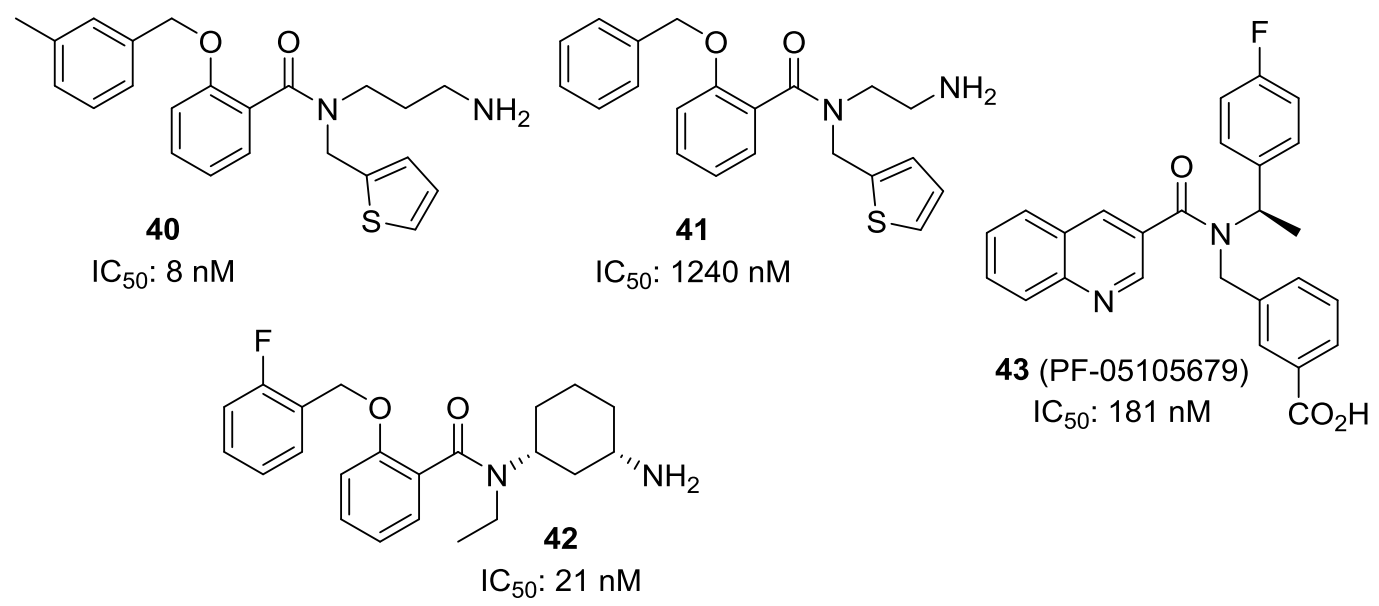

Figure 12. TRPM8 antagonists: Archetypal tertiary amide derivatives.

\subsection{Other recent TRPM8 antagonists with variable central scaffolds.}

6.6.1. Cyclohexane-hydantoine spirocyclic derivatives. Patent WO2015136947 from Raqualia Pharma Inc. communicates the preparation of a big collection of 1,3diazaspiro[4.5]decane-2,4-dione derivatives and their 1-oxa-3-azaspiro analogues ( 600 examples), among which an array of 42 compounds potently inhibited the $\mathrm{Ca}^{2+}$ influx through HEK293 cell expressing hTRPM8 $\left(\mathrm{IC}_{50}<10 \mathrm{nM}\right.$, i.e. 44, Figure 13). ${ }^{193}$ Although a central phenyl ring seems to be preferred, some heterocyclic moieties, like pyridine, imidazole and pyrrole are allowed at this position. The phenyl ring could bear a diverse set of nitrogen heterocycles, including indole, 1-benzimidazole, isoquinoline, 
and different aza analogues, with the 7-aza-1-benzimidazole as the most repetitive motif in highly active compounds. Although without displaying specific data, the inventors claimed for in vitro inhibition of the $\mathrm{Ca}^{2+}$ influx through a melanoma cell line (G-31), and potent in vivo activities in different neuropathic pain models and on micturition frequency.<smiles></smiles><smiles>CCn1nnc(-c2sc(-c3cccc(F)c3)nc2O)n1</smiles><smiles>CC1CCC(C(C)C)C(NC(=O)c2ccc(-c3ccccc3)cc2)C1</smiles><smiles>COC(=O)C(NC(=O)OCc1ccccc1)C(Cc1ccccc1)NCc1ccccc1</smiles><smiles>O=C(/C=C/c1cccc([N+](=O)[O-])c1)Nc1cccc(I)c1</smiles><smiles>Cc1cc(C)c2c(c1)/C(=C/c1ccccc1)OC2=O</smiles>

50

$\mathrm{IC}_{50}: 1 \mu \mathrm{M}$<smiles>Clc1ccccc1C(c1ccccc1)(c1ccccc1)n1ccnc1</smiles>

Clotrimazole $\mathrm{IC}_{50}: 8 \mu \mathrm{M}$<smiles>Clc1ccc(COC(Cn2ccnc2)c2ccc(Cl)cc2Cl)cc1</smiles>

Econazole $\mathrm{IC}_{50}: 0.42 \mu \mathrm{M}$

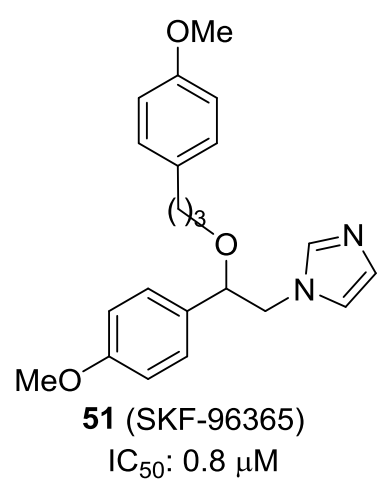

Figure 13. Structure of other structurally diverse TRPM8 antagonists.

6.6.2. Thiazole derivatives. A patent from Dompé Farmaceutici SpA revealed a series of compounds with a thiazole or isoxazole central scaffold with interesting activities as TRPM8 antagonists in vitro and in vivo. ${ }^{194}$ The phenyl thiazole derivative (DFL23448, 45), was then fully characterized in collaboration with different academic groups. ${ }^{195}$ It 
shows an $\mathrm{IC}_{50}$ value of $10 \mathrm{nM}$ in cold-activated hTRPM8 HEK-293 cells, being selective against other TRP channels (TRPV1, TRPA1, TRPV4) and different Gprotein-coupled receptors. In in vivo experiments in rats, $\mathbf{4 5}$ is able to reduce icilininduced wet-dog shakes $(10 \mathrm{mg} / \mathrm{kg}$, i.v), prolongs the storage phase of micturition and inhibits bladder overactivity.

6.6.3. Menthol derivatives. A series of menthylamine derivatives, embodied by compound 46, elicited potent TRPM8 antagonist properties, being between 4- and 150fold selective against TRPV1 and TRPA1 channels. ${ }^{196}$ When tested on a human androgen-responsive prostate carcinoma cell line, which over-expresses TRPM8, compound 46 induces apoptosis, measured by the release of caspase 3/7. However, in the androgen-unresponsive DU-145 tumor cell line, this compound is inactive, indicating a TRPM8-dependent antitumor activity. This compound was also progressed to $\mathrm{Ph}$ I clinical trials.

6.6.4. Chroman derivatives. A big series of azachroman derivatives was protected under patent WO 2014025651 by Amgen Inc. ${ }^{197}$ Exemplified here by compound 47, a number of these derivatives displayed nanomolar activity in the luminescence assay of intracellular calcium (CHO expressing hTRPM8). The most potent antagonists were able to inhibit $>90 \%$ the wet-dog shakes in rats at $1 \mathrm{mg} / \mathrm{Kg}$ dose. These compounds combine in the molecule key structural elements of other families of TRPM8 antagonists, akin to the chroman heterocyclic ring present in 34 (Figure 9) and a heterocyclic moiety, like the benzimidazole profusely used within the sulfonamide derivatives.

Clinical trials (Phase I, NCT01953341, NCT02132429) have been started with AMG333 (structure not disclosed) to define safety and tolerability, and to characterize the pharmacokinetic (PK) profile, as well as its effect on the cold pressor test (CPT)- 
induced increase in blood pressure after single oral doses in healthy individuals and subjects with migraine.

6.6.5. $\boldsymbol{\beta}, \boldsymbol{\gamma}$-Diaminoesters. Selective antagonists for TRPV1, TRPM8 (48) and TRPA1 channels, as well as dual TRPV1/TRPM8 and TRPM8/TRPA1 ligands, were obtained after modification of a linear $\beta, \gamma$-diaminoester scaffold. ${ }^{198}$ In this family, no significant differences in activity were found among diastereoisomers of the same compound, suggesting that they could accommodate within a big pocket within these TRP channels. Lessons extracted from the preferred substituents for the selective blockade of these three TRP channels could serve to design new potent and selective TRP blockers.

6.6.6. Cinnamamide derivatives. Some open-chain cinnamamide derivatives, as 49, primarily prepared as intermediates in the synthesis of icilin derivatives, displayed pronounced TRPM8 antagonist activity and acceptable selectivity over TRPV1. ${ }^{146}$ Halogens or aliphatic groups at meta-position of the aniline-derived ring provide the most potent antagonists, with the $m$-iodo derivative 49 showing a $73 \mathrm{nM} \mathrm{IC} \mathrm{I}_{50}$ value.

6.6.7. 3-Ylidenephthalides. A new template that resulted in novel TRP channel modulators was the 3-ylidenephthalides. Thus, Ortar and coworkers described that these type of compounds act as TRPM8 antagonists (50, Figure 13), but also as strong modulators of TRPA1 (activators and desensitizers). ${ }^{199}$

6.6.8. Others. Some approved antifungal drugs as clotrimazole and econazole are also good blockers of TRPM8 channels. ${ }^{200,} 201$ The phenylethyl imidazole (SKF-96365, 51), ${ }^{202}$ an inhibitor of receptor-mediated $\mathrm{Ca}^{2+}$ entry with blocking actions on several TRPC channels, also targets and blocks TRPM8 receptors $\left(\mathrm{IC}_{50}=0.8 \mu \mathrm{M}\right){ }^{51}$

\subsection{Natural products and derivatives as TRPM8 antagonists}


The well-known TRPV1 activators capsaicin and resiniferatoxin inhibit the effect on $\mathrm{Ca}^{2+}$ induced by icilin, but not by menthol, on TRPM8-HEK-293 cells (micromolar and submicromolar potencies, respectively). ${ }^{203}$ Anandamide and N-arachidonoyl-dopamine (NADA, Figure 14), ${ }^{204}$ endogenous ligands of TRPV1 and CB1 receptors, behaved as TRPM8 antagonists by inhibiting the $\mathrm{Ca}^{2+}$ entry stimulated both by icilin and menthol. ${ }^{203}$ Similarly, other cannabinoid structures of natural origin, like THC, THCA, cannabigerol, and cannabidiol are able to block the TRPM8 channel activation, but in general are nonselective against other TRP channels. ${ }^{205}$ Cannabigerol, a known nonpsychotropic cannabinoid is able to reduce cell viability in the colorectal cancer cell line CACO-2 by promoting apoptosis, which was confirmed by the increased activity of caspase $3 / 7 .^{206}$ This effect on cell viability was mimicked by two other phytocannabinoids, which also block TRPM8, and what is more important, TRPM8 silencing resulted in a lower cytotoxic effect. In vivo experiments performed both in xenograft and AOM (azoxymethane) models of colon cancer showed that cannabigerol reduces and even prevents the tumor growth. The antitumor activity of cannabidiol on prostate cancer cell lines has also been reported. ${ }^{207}$ These results suggest cannabigerol, cannabidiol and related non-habit analogues could be promising agents in cancer treatment.

Sphingoid-like compounds, like leucettamols A and B obtained from a marine sponge, inhibit icilin-induced activation of TRPM8 channels. ${ }^{208}$ These compounds also target the cold-sensitive TRPA1 receptors, but are inactive on TRPV1 and the cannabinoid receptors.

Some geraniol, nerol, and citronellol derivatives behave as TRPM8 antagonists on TRPM8-HEK293 cells, the nerol chain being particularly effective in this respect. Compound 52, with an $\mathrm{IC}_{50}$ value of $0.29 \mu \mathrm{M}$ in the TRPM8 assay, was selective 
against TRPV1 but acts as a strong modulator of TRPA1 channels ( $\mathrm{EC}_{50}$ and/or $\mathrm{IC}_{50}$ values $\left.<1 \mu \mathrm{M}\right) .{ }^{209}$ Similarly, thymol derivatives, here exemplified by compound 53, are true TRPM8 antagonists, but as for most phytochemicals with TRPM8 activity, also display strong TRPA1 modulation. ${ }^{210}$
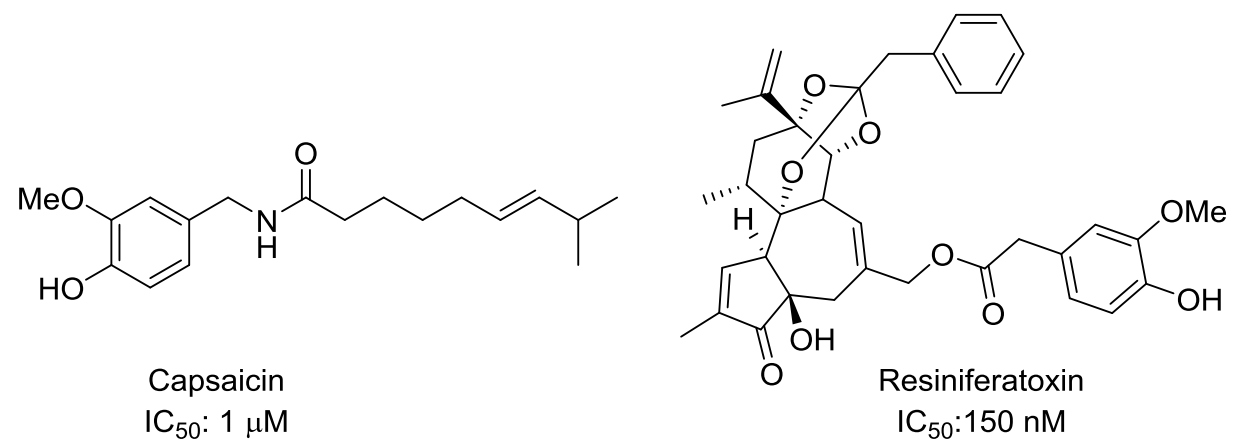

Capsaicin

$\mathrm{IC}_{50}: 1 \mu \mathrm{M}$<smiles>CCCCC/C=C/C/C=C/C/C=C/CCCC(=O)NCCc1ccc(O)c(O)c1</smiles>

Anandamide

$\mathrm{IC}_{50}: 150 \mathrm{nM}$

NADA

$\mathrm{IC}_{50}: 0.7 \mu \mathrm{M}$<smiles>CCCCCc1cc(O)c2c(c1)OC(C)[C@H]1CCC(C)=C[C@H]21</smiles>

THC

$\mathrm{IC}_{50}: 0.16 \mu \mathrm{M}$<smiles>CCCCCc1cc2c(c(O)c1C(=O)O)[C@H]1C=C(C)CC[C@H]1C(C)(C)O2</smiles>

THCA

$I_{50}: 0.15 \mu \mathrm{M}$<smiles>CCCCCc1cc(O)c(CC=C(C)CCC=C(C)C)c(O)c1</smiles>

Cannabigerol

$\mathrm{IC}_{50}: 0.16 \mu \mathrm{M}$<smiles>CCCCCc1cc(O)c([C@H]2C=C(C)CC[C@H]2C(C)C)c(O)c1</smiles>

Cannabidiol

$\mathrm{IC}_{50}: 0.06 \mu \mathrm{M}$<smiles></smiles>

52

$\mathrm{IC}_{50}: 0.29 \mu \mathrm{M}$<smiles>Cc1ccc(C(C)C)c(NC(=O)CCCCCCc2ccccc2)c1</smiles>

$\mathrm{IC}_{50}: 0.3 \mu \mathrm{M}$

Figure 14. Structure of phytochemicals and derivatives acting as TRPM8 antagonists. 


\section{INSIGHTS INTO THE TRPM8 STRUCTURE}

In the lack of a crystal structure, little is known about the structure-function of TRPM8, and the scarce structural information available is coming from mutagenesis experiments and molecular modeling studies.

Similarly to voltage-gated potassium (Kv) and like other TRPs, TRPM8 channels have six $\alpha$-helices forming the transmembrane architecture (S1-S6). Among them, S1-S4 segments constitute the sensing domain (SD) and S5 and S6 constitute the pore (PD). The intracellular $\mathrm{N}$-domain, with an important role in targeting TRPM8 to the plasma membrane, and also the inner $C$-terminal domain, containing the TRP and coiled-coil subdomains required for gating and channel assembly, complete the protein. ${ }^{211,212}$ The S4 transmembrane and the S4-S5 linker are responsible for voltage sensing, S6 is involved in the selectivity for cations, and the S2-S3 linker seems to be implicated in the interaction with icilin, the same region that has been recognized in the activation of other TRPs by chemical agonists. ${ }^{213}$ It has been demonstrated that the initial $N$-terminal region of TRPM8 is important for correct biogenesis and function, since truncation of the 1-40 segment augment TRPM8 responses to menthol and cold, and elimination of the 40-60 region afforded non-functional channels that are retained in the ER. ${ }^{214}$ The group of Edwardson, by means of atomic force microscopy (AFM) imaging, has showed that the TRPM8 channel assembles as a tetramer, with a centrally located pore. ${ }^{215}$ These authors suggestthat this assembly pattern is common to other TRP members, as they had previously shown for TRPC $1,{ }^{216}$ and recently has been elegantly confirmed by the group of Julius, which has solved the structure of TRPV1 through electron cryo-electron microscopy. ${ }^{217}$

High-throughput random mutagenesis studies on the TRPM8 thermosensor proved that residues in S2 and S4 transmembrane segments are important for menthol-induced 
channel opening, and voltage and temperature activation. ${ }^{218}$ Namely, Y745 in S2 and R842 in S4 were designated as chief residues for channel opening and menthol dependent currents through TRPM8. Y745 is also critical for the inhibition of cold- and voltage-activated TRPM8 currents mediated by $\mathbf{5 1}$, but not by other antagonists like $\mathbf{3 0}$, clotrimazole, and econazole, suggesting multiple binding sites on these channels. ${ }^{201}$ Very recent NMR experiments on the interaction between menthol and the hTRPM8SD corroborate that R842 and Y745 are essential residues for the interaction, and indicated that more likely ligand binding produces a conformational change in the sensor domain that results in channel gating. ${ }^{219}$

Chimeric TRPM8 channels containing segments of the S6-TRP box linker of TRPV1 permitted the identification of residue Tyr981 as a key molecular determinant of channel function, while mutations in the 986-990 region influenced channel gating by voltage and menthol. Based on these results and on the electron cryo-electron microscopy model of TRPV1, the group of Ferrer-Montiel generated a molecular model of TRPM8 and hypothesized that residue Tyr981 and region 986-990 may be involved in inter-subunit interactions between the TRP domain and the S4-S5 linker (Figure 15). If the TRP domain participates in channel opening, the modulation of protein-protein interactions within this domain may constitute a new strategy for channel modulation and/or drug intervention. ${ }^{220}$ 

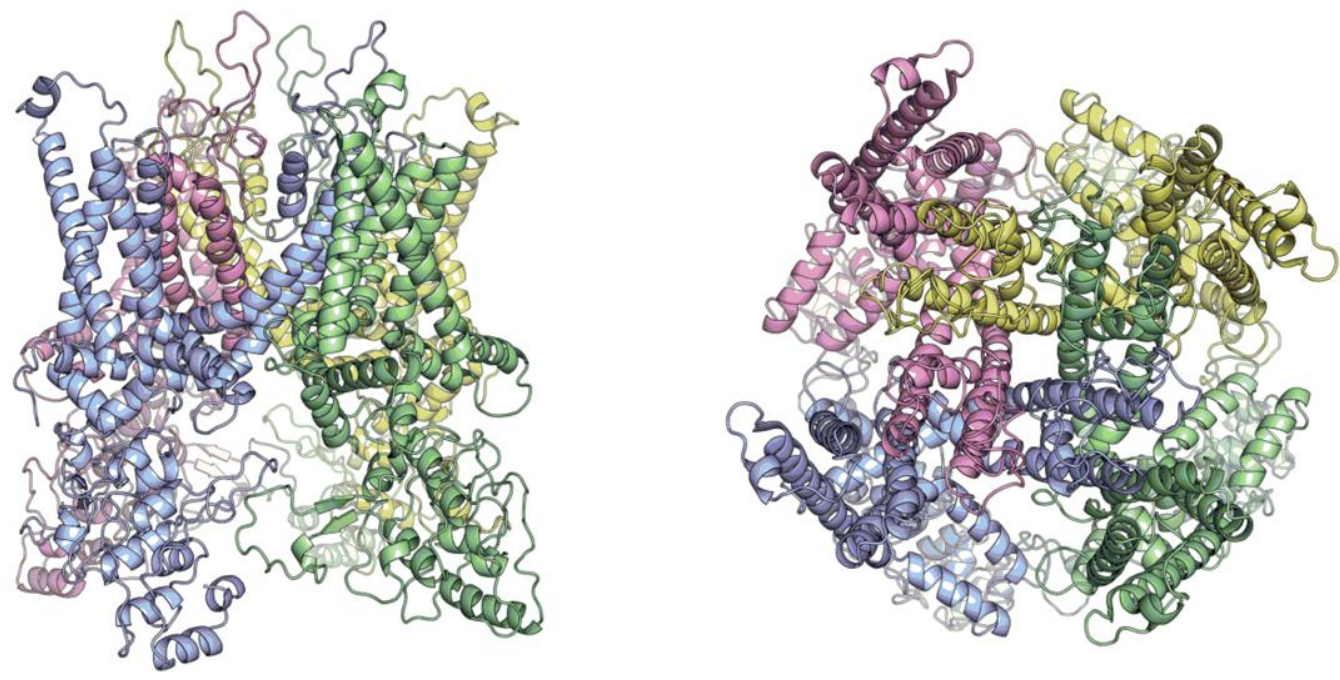

Figure 15. Homology model of the tetrameric assembly of TRPM8 channel viewed from the lateral (left) and the intracellular (right) side. Each monomer is differently colored.

Based on the above model, Bertamino et al. proposed two pharmacophore prototypes for their series of tryptamine-based TRPM8 modulators, identifying a unique binding site for both agonist and antagonist derivatives (15 and 38, Figures 5 and 11, respectively), but differing in the interaction network. ${ }^{157}$ TRPM8 complexes with these compounds are stabilized by similar hydrophobic interactions with Leu843, Ile701, Leu697, a $\pi-\pi$ stacking with Tyr754, and electrostatic pairs with the Glu1004 side chain. The indole NH proton of agonist $\mathbf{2 3}$ makes hydrogen bonds with Tyr754 phenoxy group and with the backbone of Arg1008, increasing the Arg1008-Glu1004 distance when compared to that measured for the TRPM8-38 complex, and promoting an evident shift of the TRP domain helix. Further mutagenesis studies are needed to corroborate the structural hypothesis depicted from these pharmacophore models.

Pedretti and coworkers generated a full-length computer model for the hTRPM8 channel, following a fragmental strategy, exploiting the homology with other channel to 
construct the monomer, namely the voltage-dependent Shaker family of K+ channel for the transmembrane region and the structure of $\mathrm{HCN} 2$ channel for the $\mathrm{C}$-terminal domain. $^{221}$ Protein-protein docking was then used to assemble monomers into the corresponding homotetramer. Docking with menthol, icilin and other ligands resulted in good agreement with mutagenesis studies, confirming that S4 and S4-S5 loop are crucial for channel activation.

The TRPM8 transmembrane and pore helix region has been studied by Bidaux et al. using a combination of molecular modeling and experimental techniques. ${ }^{222}$ As for other members of the TRP family, they identified that the DDDD ring was essential for the pore of TRPM8, with the length of side-chains and the negative charges of these residues being crucial in TRPM8. However, unlike for other TRP channels, the negative charge of TRPM8 D920 residue is not enough to select divalent cations, but participates to the facilitation of cation conductance. This study also demonstrated that residue Y908 in the P-helix is implicated in menthol and cold-mediated TRPM8 activity, but not in icilin recognition. Whether menthol binds directly to the P-helix or to the binding site on the S2 pocket, inducing a conformational change on the pore domain remains to be elucidated.

\section{ENDOGENOUS REGULATION OF TRPM8}

Traditionally, a large effort has been devoted to modulate ion channels, including TRPM8, considering that they are isolated proteins inserted in a cell membrane. However, it is becoming evident that ion channels are members of protein networks that notably influence their activity. Furthermore, channel activity is highly regulated in a context-dependent manner, with the interplay of diverse cellular components, including lipids, proteins and metabolites. In this regard, the activity of TRPM8 is prone to 
endogenous regulation for fine-tuning its activity to a proper cellular response. Accordingly, TRPM8 dysfunction appears also affected by regulatory pathways, as their malfunction may impact TRPM8 function. ${ }^{223}$ Undoubtedly, the most studied endogenous TRPM8 regulatory mechanism is its dependence on $\mathrm{PI}(4,5) \mathrm{P}_{2} \cdot{ }^{31}$ It is well documented that $\mathrm{PI}(4,5) \mathrm{P}_{2}$ modulates both activation and desensitization of the channel. ${ }^{31}$ Hydrolysis of PI(4,5) $\mathrm{P}_{2}$ by phospholipases type C (PLC $\gamma, \operatorname{PLC} \beta$ and PLC $\delta$ ) abrogates channel function, while resynthesis of the original $\mathrm{PIP}_{2}$ restores its channel activation. ${ }^{223}$ Regulation of TRPM8 by phosphoinositides can also be mediated by the phosphoinositide interacting regulator of TRP (Pirt), a protein that increases the sensitivity of TRPM8 to menthol and cool temperatures. ${ }^{224}$ This protein acts synergistically with $\mathrm{PI}(4,5) \mathrm{P}_{2}$ to augment TRPM8 channel activity. ${ }^{225}$

$\mathrm{PI}(4,5) \mathrm{P}_{2}$ levels are largely modulated by the activation of PLC through G-protein coupled receptors (GPCR) and Receptor Tyrosine Kinase (RTK). Activated PLC enzymes hydrolyze $\mathrm{PI}(4,5) \mathrm{P}_{2}$ to phosphoinositol trisphospate $\left(\mathrm{PIP}_{3}\right)$ and diacylglycerol (DAG). These two components act synergistically to activate PKC, which in turn may phosphorylate TRPM8. Furthermore, PIP3-induced release of $\mathrm{Ca}^{2+}$ from the endoplasmic reticulum activates calmodulin kinase that can also phosphorylate TRPM8. ${ }^{226}$ A consequence of TRPM8 phosphorylation appears to be reduction of channel activity that further augments the inhibition produced by the hydrolysis of $\mathrm{PI}(4,5) \mathrm{P}_{2}$. Complementarily, an increase in PKA activity also appears to inhibit TRPM8 channel activity. Recently, a novel mechanism of TRPM8 inhibition by GPCRs that implies the direct inhibition of the channel by $\mathrm{G} \alpha_{\mathrm{q}}$ has been described. ${ }^{227}$ It is notable that most RTK and GPCRs sensitize TRPV1 channels, and concomitantly desensitize TRPM8 channels, which may underlie the heat hyperalgesia and abnormal cold sensations caused by inflammation. ${ }^{227}$ 
The activity of TRPM8 is additionally modulated through two additional membranerelated mechanisms. First, it has been documented its regulation by phospholipase $A_{2}$ $\left(\mathrm{PLA}_{2}\right)$, an enzyme that generates lysophospholipids and arachidonic acid. ${ }^{23}$ Intriguingly, these lipids modulate TRPM8 activity in some cellular systems but not in planar lipid bilayers. A plausible explanation is that $\mathrm{PLA}_{2}$ generates two antagonistic compounds as lysophospholipids tend to enhance TRPM8 activity and arachidonic acid inhibits the channel function. ${ }^{228}$ Because PLA 2 normally enhance the menthol activity, it appears a prevalence of the lysophospholipid stimulating effect over the polyunsaturated fatty acids inhibitory action. Second, TRPM8 activity is also modulated by its location in membrane microdomains. For instance, it was reported that TRPM8 activity is downregulated by its partition in lipid rafts. ${ }^{229}$ However, a recent study reported just an opposite result as TRPM8 activity was reduced after disrupting the lipid rafts in trigeminal neurons. ${ }^{230}$ These results indicate a role of membrane microdomains modulating channel function although further studies are needed to clarify whether the discrepancies reported are due to different experimental conditions or determined by the cellular context. Finally, the oxidative metabolite of linoleic acid 9(S)-HODE acts a non-selective TRPM8 antagonist, which also modulates TRPV1 and TRPA1 channels. $^{231}$

Apart from the lipid-mediated endogenous regulation, there is evidence that TRPM8 function can be additionally modulated by short isoforms that emerge from posttranscriptional regulation of the main protein transcript. ${ }^{232}$ These shorter channel isoforms inhibit TRPM8 activity by mimicking an increase in temperature as compared with the inhibitory activity exerted by chemical antagonists. ${ }^{232}$ Interestingly, a novel TRPM8 isoform has been identified in keratinocytes that is expressed in the endoplasmic reticulum of these cells, and endogenously contributes to the cold 
sensitivity of epidermal homeostasis by controlling the balance between keratinocyte proliferation and differentiation in a cold-dependent manner. ${ }^{233}$ Recently, it has been described that the vesicle-associated membrane protein 7 (VAMP7) is implicated in the functional plasma membrane incorporation of TRPM8, and therefore in regulating thermosensitivity. ${ }^{234}$

Another important endogenous regulatory mechanism of TRPM8 arises from its sensitivity to sex hormones. As already mentioned, this channel was first identified as a biomarker of hormone-dependent prostate cancer cells, as its levels were high in these tumor cells. ${ }^{11}$ Asuthkar et al. report the interesting observation that the TRPM8 channel is a receptor for testosterone, suggesting a direct role of the hormone regulating the receptor activity. ${ }^{235,236}$ Related to this observation, Gkika et al. discovered that the prostate cancer marker, prostate-specific antigen (PSA), is also a modulator of TRPM8 activity. ${ }^{237}$ Indeed, they reported that PSA acts as a natural agonist of TRPM8 in the prostate and the channel activation by PSA results in a reduction of cancer cell motility. Overall, these findings suggest that modulation of TRPM8 may be an important strategy for anti-cancer drug intervention.

In summary, endogenous regulation of TRPM8 channels provides new opportunities to modulate the receptor activity by acting in signaling pathways that convey into the channel.

\section{SUMMARY AND FUTURE PERSPECTIVES}

Over the past few years, there has been significant development in the field of TRPM8 channels, regarding expression, polymodal activation, implication in diverse pathological conditions, and discovery of diverse modulators, both agonists and 
antagonists. $^{25,33}$ Cumulative evidence indicates the essential role of TRPM8 in virtually all aspects of cold thermal transduction, including innocuous and noxious cold, hypersensitivity to cold caused by inflammation, nerve injury or chemotherapeutic

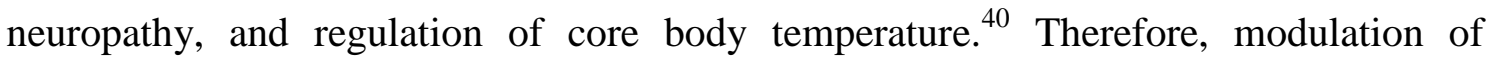
TRPM8 channel function to tune the excitability of cold-sensing neurons could have a broad clinical benefit in the management of chronic and/or neuropathic pain. ${ }^{44}$ Thus, the identification of new compounds targeting different binding sites of its signalplex may be anticipated as a realistic strategy for effectively and safely treating acute and chronic pain states, which is still a major unmet challenge in biomedical research. Regarding cancer, it is documented that in prostate tissues, TRPM8 channels play a different role depending of the cell type and also on the tumor grade, and progression, showing even different and opposite effects. ${ }^{89}$ TRPM8 expression in prostate cancer cells is androgenregulated, but its over-expression appears to be hormone-independent. TRPM8 expression is substantially decreased in androgen-independent and metastatic prostate cancer. A number of other life-threatening tumors, like melanoma, neuroblastoma, and pancreatic adenocarcinoma, also over-express TRPM8 channels, although their particular role is mostly unknown. ${ }^{88}$ Therefore, there is still further research needed to completely elucidate the mechanisms by which TRPM8 exerts its biological activity and to understand its implications in tumorigenesis and cancer progression. Provided that activation or blockade of the TRPM8 channels may have opposite effects, depending on the type and stage of the tumor, their clinical significance remains to be proved. The proven involvement of TRPM8 channels in pain, cancer, and cancer-induced pain, and its validation as a molecular target, open the door to new global strategies for effective management of these pathologies. Concerning diagnosis, TRPM8 levels could be exploited as a clinical biomarker for the diagnosis of different cancer types. In fact, the 
TRPM8 detection in patient fluids samples (urine and blood) proved to be useful to discriminate between clinically localized prostate cancer and metastatic tumors. ${ }^{86,} 101$ Furthermore, molecular imaging agents based on TRPM8 selective modulators could also have a major effect on the detection of cancer, as already proposed. ${ }^{126}$

Increasing experimental evidences have also revealed that stimulation of TRPM8 channels is involved in a number of pathological conditions, including thermogenesis of brown adipose tissue, ${ }^{113}$ asthma and COPD, ${ }^{238}$ urinary tract dysfunction, ${ }^{239}$ and eye wetness. $^{121}$ Thus, TRPM8 provides promising new approaches to treat obesity, respiratory processes, bladder dysfunction, and certain ophthalmologic problems.

Although a number of diverse TRPM8 modulators have been described, and resulted in an improved understanding of the structure-activity relationships within different families, their selectivity over other TRP channels, and in general over panels of diverse biological targets, is mostly unknown or not yet disclosed. Furthermore, taking into account that a unique chemotype could result in promiscuous ligands for different TRP channels, ${ }^{198}$ the existing pharmacological knowledge about TRPM8 modulators should be taken with caution. Another factor of paramount importance for the advancement in TRPM8 drug discovery will be to elucidate the receptor binding sites for the different families of modulators. At present, this is partly precluded by the scarce structural knowledge available, although progress in homology modeling may contribute in the near future. ${ }^{157}$ It is expected that further advances in structural biology could help in characterizing accurately TRPM8 ion channel-ligand interactions, thus increasing our understanding of ligand binding. In addition, it will contribute to apply rational design methodologies to hit discovery and to hit-to-lead optimization toward safer and more selective modulators. Nonetheless, until this information becomes available, existing 
screening methodologies provide a useful approach to discover novel TRPM8 modulators and to develop analogues with improved therapeutic properties.

As reviewed in this perspective, there are already few TRPM8 modulators that have reached clinical studies, and most of them are yet in phase I trials. Although the expectations are high, prediction of a clinical success based only on animal data appears premature at present. We have to wait for the results of proof-of-concept clinical studies to learn on the relevance of therapies based on TRPM8 modulators.

Finally, the information accrued thus far also suggests that the operational function of TRPM8 depends on the cellular context and that different strategies, from membrane localization and dynamics to translation of short isoforms, are involved in defining the pathophysiological function of the receptor. This information should be taken into account in the design of the next generation of TRPM8 therapeutic drug candidates. Structure-function studies have unveiled that the TRP domain, ${ }^{31}$ a protein region adjacent to the channel gate, contributes to the allosteric coupling of stimuli sensing to gate opening, and it is the binding site of PI $(4,5) \mathrm{P} 2 .{ }^{220,}{ }^{240}$ Notably, peptides patterned after this domain in TRPV1 channels inhibit receptor function, ${ }^{228}$ indicating that this domain may also be a novel site for drug intervention in TRPM8 channels. Up to date, the destabilization of protein-protein interactions (PPI) within ion channels has barely been studied, ${ }^{241}$ but most probably the application of strategies followed for other PPIs could also be relevant for TRPM8 drug discovery.

Another important point to be explored in the near future would be to analyze the clinical benefit of combined therapies or multifunctional drugs acting simultaneously on several TRPs, since sometimes more than one TRP channel is involved in the same pathological disorder (i.e., TRPM8 and TRPA1 in cold-induced pain and asthma). ${ }^{107,}$ 108,242 
Although ion channels remain underexploited in drug development, continued investigation into the discovery of new, selective TRPM8 agonists and antagonists will undoubtedly contribute to future progress in the field. The ability to combine advances in functional screening, biophysical characterization, and structure-based design techniques, along with the generation of new chemical space to target ion channels will constitute a substantial challenge for the drug discovery community in the following decade. We should be expectant for the clinical success of currently tested TRPM8 modulators for the treatment of human diseases, from pain to cancer.

\section{AUTHOR INFORMATION}

\section{Corresponding author}

Rosario González-Muñiz, IQM-CSIC

rosario.gonzalezmuniz@iqm.csic.es

\section{Notes}

The authors declare no competing financial interest.

\section{Biographies}

M. J. Pérez de Vega received her MD in 1982 and her PhD in 1987 from Murcia University in Spain. After a 1-year postdoctoral fellowship at the College de France (Paris) under the supervision of Prof. J. M. Lehn, in 1990, she started to work as a Medicinal Chemist at the company Knoll S.A., pharmaceutical division of B.A.S.F., in Madrid. Currently, she is a staff scientist at the Instituto de Química Médica (CSIC), where she is Deputy Director since 2015. Her research interests include the design and synthesis of small molecules, peptides and peptidomimetics and focused to their therapeutic application, in particular in cancer, pain and neurodegenerative diseases. 
Isabel Gómez-Monterrey obtained a Ph. D. at the University of Extremadura under the supervision of Prof. Mota in 1986. After a postdoctoral fellowship at the Institute of Medicinal Chemistry (CSIC, Madrid) and at the University René Descartes of Paris, she commenced its academic career at the University of Naples in 2004. Since 2015, she is Associate Professor of Medicinal Chemistry at the same university. Prof GomezMonterrey research activity focuses on the chemistry and medicinal chemistry of peptides, peptidomimetics, and small molecules endowed with antitumor, antimicrobial, and antiviral activities.

Antonio Ferrer-Montiel completed a Ph.D. at the University of Alicante (Spain), and carried out a postdoctoral stay at the Departments of Physics and Biology of the University of California in San Diego (1990-1998). Thereafter, he started his independent career as an Associate Professor at the University Miguel Hernández (Spain) and as a researcher of the Institute of Molecular and Cellular Biology (IBMC) in 1998. He was appointed full Professor of Biochemistry and Molecular Biology in 2007, and Director of the IBMC in 2011. He is currently the head of the sensory neurobiology group at the IBMC, and his interests are centered on understanding the underlying mechanism of nociceptor inflammatory sensitization with the aim of developing better therapeutic strategies.

Rosario González-Muñiz completed a Ph.D. in chemistry from Autónoma University in Madrid, Spain (1987), and a post-doctoral stay at René Descartes University (Paris V, 1988-1990). She currently is a staff senior scientific researcher at the Medicinal Chemistry Institute (IQM-CSIC), where she was the Deputy Director (2005-2011). She is currently the head of the peptidomimetics group at the IQM-CSIC. Specialist in peptides, peptidomimetics and bioactive small-molecules, her recent research interests 
include the design and synthesis of new modulators of protein-protein interactions, and of different types of ion channels (nicotinic, TRPs) and associated proteins.

\section{ACKNOWLEDGEMENTS}

We thank Gregorio Fernández-Ballester for the figure of the TRPM8 homology model. Funding from the Ministry of Economy and Competitiveness (BFU 2012-39092-C02; SAF2015-66275-C2-R, and the Generalitat Valenciana (PROMETEO II/2014/011).

\section{ABBREVIATIONS}

$\mathrm{AFM}=$ atomic force microscopy

AMTB $=N$-(3-aminopropyl)-2-[(3-methylphenyl)methoxy]-N-(2-thienylmethyl)benzamide $\mathrm{HCl}$

$\mathrm{AOM}=$ azoxymethane

$\mathrm{AR}=$ Androgen Receptor

BAT $=$ Brown Adipose Tissue

$\mathrm{BCTC}=3$-chloro-pyridin-2-yl)-piperazine derived urea

$\mathrm{CB} 1=$ Cannabinoid Receptor 1

$\mathrm{CCI}=$ Chronic Constrictive Injury

$\mathrm{CFA}=$ Complete Freund's Adjuvant

CGRP $=$ Calcitonin Gene-Related Peptide

COPD $=$ Chronic Obstructive Pulmonary Disease

$\mathrm{CPT}=$ cold pressor test

CSD $=$ Cortical Spreading Depression

$\mathrm{DAG}=$ Diacylglycerol

DRG $=$ Dorsal Root Ganglia 
$\mathrm{ER}=$ Estrogen Receptor

5-FU = 5-Fluorouracile

hERG = human Ether-à-go-go Related Gene

HTS = High Throughput Screening

IB4 = Isolectin B4

IDO = Idiopathic Detrusor Overactivity

LUTd $=$ Lower Urinary Tract Dysfunction

MMP-9 = Matrix Metallopeptidase 9

$\mathrm{PCa}=$ Prostate Cancer

$\mathrm{PD}=$ Pore Domain

Phg $=$ Phenylglycine

$\mathrm{PI}(4,5) \mathrm{P}_{2}=$ Phosphatidylinositol-4,5-bisphosphate

Pirt $=$ Phosphoinositide Interacting Regulator of TRP

PLC $\delta 1=$ Phospholipase $\mathrm{C} \delta 1$

PKA $=$ Protein Kinase A

$\mathrm{PKC}=$ Protein kinase $\mathrm{C}$

$\mathrm{PLA}_{2}=$ Phospholipase $\mathrm{A}_{2}$

PSA $=$ Prostate-Specific Antigen

RTK $=$ Receptor Tyrosine Kinase

$\mathrm{SD}=$ Sensing Domain

$\mathrm{SNL}=$ Spinal Nerve-Ligated

$\mathrm{TG}=$ Trigeminal Ganglion

THC $=$ Tetrahydrocannabinol

THCA $=$ Tetrahydrocannabinolic acid

TNBS $=$ Trinitrobenzene sulfonic acid 
TRP $=$ Transient Receptor Potential

TRPM8 = Trp-p8 = MCR1 = Transient Receptor Potential Melastatin 8

UCP1 = Uncoupling Protein 1

VAMP7 = Vesicle-Associated Membrane Protein

WAT $=$ White Adipose Tissue

WDS $=$ "Wet-Dog" Shakes

\section{REFERENCES}

1. Madrid, R.; Bacigalupo, J. TRP Channels in Sensory Transduction. Springer International Publising Switzerland: 2015.

2. Islam, S. Transient Receptor Potential Channels. Springer Dordrecht Holland: 2011.

3. Hilton, J. K.; Rath, P.; Helsell, C. V. M.; Beckstein, O.; Van Horn, W. D. Understanding Thermosensitive Transient Receptor Potential Channels as Versatile Polymodal Cellular Sensors. Biochemistry 2015, 54, 2401-2413.

4. Venkatachalam, K.; Montell, C. TRP channels. In Ann. Rev. Biochem., 2007; Vol. 76, pp 387-417.

5. Patapoutian, A.; Peier, A. M.; Story, G. M.; Viswanath, V. Thermotrp Channels and Beyond: Mechanisms of Temperature Sensation Nat. Rev. Neurosci. 2003, 4, 529-539.

6. Vay, L.; Gu, C.; McNaughton, P. A. The Thermo-TRP Ion Channel Family: Properties and Therapeutic Implications. Br. J. Pharmacol. 2012, 165, 787-801.

7. Ferrer-Montiel, A.; Fernandez-Carvajal, A.; Planells-Cases, R.; Fernandez-Ballester, G.; Manuel Gonzalez-Ros, J.; Messeguer, A.; Gonzalez-Muniz, R. Advances in modulating thermosensory TRP channels. Expert Opin. Therap. Patents 2012, 22, 999-1017.

8. Holzer, P.; Izzo, A. A. The pharmacology of TRP channels. Br. J. Pharmacol. 2014, $171,2469-2473$.

9. Fernández-Carvajal, A.; Fernández-Ballester, G.; González-Muñiz, R.; FerrerMontiel, A. Pharmacology of TRP Channels. In TRP Channels in Sensory Transduction, 
Madrid, R.; Bacigalupo, J., Eds. Springer International Publishing Switzerland: 2015; pp 4171.

10. Moran, M. M.; McAlexander, M. A.; Biro, T.; Szallasi, A. Transient Receptor Potential Channels as Therapeutic Targets. Nat. Rev. Drug Discov. 2011, 10, 601-620.

11. Tsavaler, L.; Shapero, M. H.; Morkowski, S.; Laus, R. Trp-p8, A Novel ProstateSpecific Gene, is Up-Regulated in Prostate Cancer and Other Malignancies and Shares High Homology with Transient Receptor Potential Calcium Channel Proteins. Cancer Res. 2001, $61,3760-9$.

12. Liu, Y.; Qin, N. TRPM8 in Health and Disease: Cold Sensing and Beyond. Adv. Exp. Med. Biol. 2011, 704, 185-208.

13. Parra, A.; Madrid, R.; Echevarria, D.; del Olmo, S.; Morenilla-Palao, C.; Acosta, C. M.; Gallar, J.; Dhaka, A.; Viana, F.; Belmonte, C. Ocular Surface Wetness is Regulated by TRPM8Dependent Cold Thermoreceptors of the Cornea. Nat. Med. 2010, 16, 1396-1399.

14. Dhaka, A.; Earley, T. J.; Watson, J.; Patapoutian, A. Visualizing Cold Spots: TRPM8Expressing Sensory Neurons and their Projections. J. Neurosci. 2008, 28, 566-575.

15. De Blas, G. A.; Darszon, A.; Ocampo, A. Y.; Serrano, C. J.; Castellano, L. E.; HernandezGonzalez, E. O.; Chirinos, M.; Larrea, F.; Beltran, C.; Trevino, C. L. TRPM8, a Versatile Channel in Human Sperm. Plos One 2009, 4, e6095.

16. Sabnis, A. S.; Shadid, M.; Yost, G. S.; Reilly, C. A. Human Lung Epithelial Cells Express a Functional Cold-Sensing TRPM8 Variant. Am. J. Respir. Cell Mol. Biol. 2008, 39, 466-474. 17. Johnson, C. D.; Melanaphy, D.; Purse, A.; Stokesberry, S. A.; Dickson, P.; Zholos, A. V. Transient Receptor Potential Melastatin 8 Channel Involvement in the Regulation of Vascular Tone. Am. J. Physiol. Heart Circ. Physiol. 2009, 296, H1868-1877.

18. Knowlton, W. M.; McKemy, D. D. TRPM8: From Cold to Cancer, Peppermint to Pain. Curr. Pharm. Biotechnol. 2011, 12, 68-77.

19. Babes, A.; Ciobanu, A. C.; Neacsu, C.; Babes, R.-M. TRPM8, a Sensor for Mild Cooling in Mammalian Sensory Nerve Endings. Curr. Pharm. Biotechnol. 2011, 12, 78-88. 
20. Fernandez, J. A.; Scholfield, C. N.; McGeown, J. G.; Zholos, A. V. TRPM8 Cation Channel. Effects of Voltage, Cold and Menthol on Single-Channel Gating. Biophys. J. 2010, 98, 227A-227A.

21. Raddatz, N.; Castillo, J. P.; Gonzalez, C.; Alvarez, O.; Latorre, R. Temperature and Voltage Coupling to Channel Opening in Transient Receptor Potential Melastatin 8 (TRPM8). J. Biol. Chem. 2014, 289, 35438-35454.

22. Kuehn, F. J. P.; Kuehn, C.; Lueckhoff, A. Inhibition of TRPM8 by Icilin Distinct from Desensitization Induced by Menthol and Menthol Derivatives. J. Biol. Chem. 2009, 284, $4102-4111$.

23. McKemy, D. D. Therapeutic Potential of TRPM8 Modulators. Open Drug Discov. J. 2010, 2, 81-88.

24. Journigan, V. B.; Zaveri, N. T. TRPM8 ion channel ligands for new therapeutic applications and as probes to study menthol pharmacology. Life Sci. 2013, 92, 425-437.

25. Almaraz, L.; Manenschijn, J.-A.; de la Peña, E.; Viana, F. TRPM8. In Mammalian Transient Receptor Potential (TRP), Nilius, B.; Flockerzi, V., Eds. Springer-Verlag: Berlin, 2014; pp 547-577.

26. Chuang, H. H.; Neuhausser, W. M.; Julius, D. The Super-Cooling Agent Icilin Reveals a Mechanism of Coincidence Detection by a Temperature-Sensitive TRP Channel. Neuron 2004, 43, 859-869.

27. Proudfoot, C. J.; Garry, E. M.; Cottrell, D. F.; Rosie, R.; Anderson, H.; Robertson, D. C.; Fleetwood-Walker, S. M.; Mitchel, R. Analgesia Mediated by the TRPM8 Cold Receptor in Chronic Neuropathic Pain. Curr. Biol. 2006, 16, 1591-1605.

28. Xing, H.; Chen, M.; Ling, J.; Tan, W.; Gu, J. G. TRPM8 Mechanism of Cold Allodynia after Chronic Nerve Injury. J. Neurosci. 2007, 27, 13680-13690.

29. Yamamura, H.; Ugawa, S.; Ueda, T.; Morita, A.; Shimada, S. TRPM8 Activation Suppresses Cellular Viability in Human Melanoma. Am. J. Physiol. Cell Physiol. 2008, 295, C296-301. 
30. Gordon-Shaag, A.; Zaggota, W. N.; Gordon, S. E. Mechanism of Ca2+-Dependent Desensitization in TRP Channels. Channels 2008, 2, 125-129.

31. Rohacs, T.; Lopes, C. M. B.; Michailidis, I.; Logothetis, D. E. PI(4,5)P-2 Regulates the Activation and Desensitization of TRPM8 Channels through the TRP Domain. Nat. Neurosci. 2005, 8, 626-634.

32. Abe, J.; Hosokawa, H.; Sawada, Y.; Matsumura, K.; Kobayashi, S. Ca2+-Dependent PKC Activation MediatesMenthol-Induced Desensitization ofTransient Receptor Potential M8. Neurosci. Lett. 2006, 397, 140-144.

33. Malkia, A.; Morenilla-Palao, C.; Viana, F. The Emerging Pharmacology of TRPM8 Channels: Hidden Therapeutic Potential Underneath a Cold Surface. Curr. Pharm. Biotechnol. 2011, 12, 54-67.

34. Cohen, S. P.; Raja, S. N. Pain. . In Goldman-Cecil Medicine 25th edition, Goldman, l.; Schafer, a. i., Eds. International Edition: Elsevier: 2015; pp 133-143.

35. Woolf, C. J.; Ma, Q. Nociceptors-Noxious Stimulus Detectors. Neuron 2007, 55, 353364.

36. Hucho, T.; Levine, J. D. Signaling Pathways in Sensitization: Toward a Nociceptor Cell Biology. Neuron 2007, 55, 365-376.

37. Baron, R. Neuropathic pain: a clinical perspective. In Handbook of Experimental Pharmacology, Canning, B. J.; Spina, D., Eds. 2009; pp 3-30.

38. Pfau, D. B.; Krumova, E. K.; Treede, R.-D.; Baron, R.; Toelle, T.; Birklein, F.; Eich, W.; Geber, C.; Gerhardt, A.; Weiss, T.; Magerl, W.; Maier, C. Quantitative Sensory Testing in the German Research Network on Neuropathic Pain (DFNS): Reference Data for the Trunk and Application in Patients with Chronic Postherpetic Neuralgia. Pain 2014, 155, 1002-1015. 39. Schaible, H. G. Peripheral and Central Mechanisms of Pain Generation. In Handbook of Experimental Pharmacology, Pingle, S. C.; Matta, J. A.; Ahern, G. P., Eds. Springer: 2007; pp 3-28. 
40. Patapoutian, A.; Tate, S.; Woolf, C. J. Transient Receptor Potential Channels: Targeting Pain at the Source. Nat. Rev. Drug Discov. 2009, 8, 55-68.

41. Levine, J. D.; Alessandri-Haber, N. TRP Channels: Targets for the Relief of Pain. BBA-Mol. Basis Dis. 2007, 1772, 989-1003.

42. Premkumar, L. S.; Abooj, M. TRP Channels and Analgesia. Life Sci. 2013, 92, 415424.

43. Basbaum, A. I.; Bautista, D. M.; Scherrer, G.; Julius, D. Cellular and Molecular Mechanisms of Pain. Cell 2009, 139, 267-284.

44. Belmonte, C.; Brock, J. A.; Viana, F. Converting Cold into Pain. Exp. Brain Res. 2009, $196,13-30$.

45. Peier, A. M.; Moqrich, A.; Hergarden, A. C.; Reeve, A. J.; Andersson, D. A.; Story, G. M.; Earley, T. J.; Dragoni, I.; McIntyre, P.; Bevan, S.; Patapoutian, A. A TRP Channel that Senses Cold Stimuli and Menthol. Cell 2002, 108, 705-715.

46. McCoy, D. D.; Knowlton, W. M.; McKemy, D. D. Scraping through the Ice: Uncovering the Role of TRPM8 in Cold Transduction. Am. J. Physiol.-Reg. I. 2011, 300, R1278-R1287.

47. Thut, P. D.; Wrigley, D.; Gold, M. S. Cold Transduction in Rat Trigeminal Ganglia Neurons in vitro. Neurosci. 2003, 119, 1071-1083.

48. Babes, A.; Zorzon, D.; Reid, G. Two Populations of Cold-Sensitive Neurons in Rat Dorsal Root Ganglia and their Modulation by Nerve Growth Factor. Eur. J. Neurosci. 2004, $20,2276-2282$.

49. Kobayashi, K.; Fukuoka, T.; Obata, K.; Yamanaka, H.; Dai, Y.; Tokunaga, A.; Noguchi, K. Distinct Expression of TRPM8, TRPA1, and TRPV1 mRNAs in Rat Primary Afferent

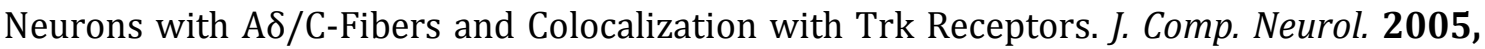
493, 596-606.

50. Takashima, Y.; Daniels, R. L.; Knowlton, W.; Teng, J.; Liman, E. R.; McKemy, D. D. Diversity in the Neural Circuitry of Cold Sensing Revealed by Genetic Axonal Labeling of Transient Receptor Potential Melastatin 8 Neurons. J. Neurosci. 2007, 27, 14147-14157. 
51. Madrid, R.; Donovan-Rodriguez, T.; Meseguer, V.; Acosta, M. C.; Belmonte, C.; Viana, F. Contribution of TRPM8 Channels to Cold Transduction in Primary Sensory Neurons and Peripheral Nerve Terminals. J. Neurosci. 2006, 26, 12512-12525.

52. Bautista, D. M.; Siemens, J.; Glazer, J. M.; Tsuruda, P. R.; Basbaum, A. I.; Stucky, C. L.; Jordt, S.-E.; Julius, D. The Menthol Receptor TRPM8 is the Principal Detector of environmental Cold. Nature 2007, 448, 204-208.

53. Dhaka, A.; Murray, A. N.; Mathur, J.; Earley, T. J.; Petrus, M. J.; Patapoutian, A. TRPM8 is Required for Cold Sensation in Mice. Neuron 2007, 54, 371-378.

54. Knowlton, W. M.; Bifolck-Fisher, A.; Bautista, D. M.; McKemy, D. D. TRPM8, but not TRPA1, Is Required for Neural and Behavioral Responses to Acute Noxious Cold Temperatures and Cold-Mimetics in vivo. Pain 2010, 150, 340-350.

55. Ramachandran, R.; Hyun, E.; Zhao, L.; Lapointe, T. K.; Chapman, K.; Hirota, C. L.; Ghosh, S.; McKemy, D. D.; Vergnolle, N.; Beck, P. L.; Altier, C.; Hollenberg, M. D. TRPM8 Activation Attenuates Inflammatory Responses in Mouse Models of Colitis. Proc. Natl. Acad. Sci. USA 2013, 110, 7476-7481.

56. Colburn, R. W.; Lubin, M. L.; Stone, D. J., Jr.; Wang, Y.; Lawrence, D.; D'Andrea, M. R.; Brandt, M. R.; Liu, Y.; Flores, C. M.; Qin, N. Attenuated Cold Sensitivity in TRPM8 Null Mice. Neuron 2007, 54, 379-386.

57. Parks, D. J.; Parsons, W. H.; Colburn, R. W.; Meegalla, S. K.; Ballentine, S. K.; Illig, C. R.; Qin, N.; Liu, Y.; Hutchinson, T. L.; Lubin, M. L.; Stone, D. J., Jr.; Baker, J. F.; Schneider, C. R.; Ma, J.; Damiano, B. P.; Flores, C. M.; Player, M. R. Design and Optimization of Benzimidazole-Containing Transient Receptor Potential Melastatin 8 (TRPM8) Antagonists. J. Med. Chem. 2011, 54, 233-247.

58. Hosoya, T.; Matsumoto, K.; Tashima, K.; Nakamura, H.; Fujino, H.; Murayama, T.; Horie, S. TRPM8 Has a Key Role in Experimental Colitis-Induced Visceral Hyperalgesia in Mice. Neurogastroenterol. Motil. 2014, 26, 1112-1121. 
59. Zuo, X.; Ling, J. X.; Xu, G.-Y.; Gu, J. G. Operant Behavioral Responses to Orofacial Cold Stimuli in Rats with Chronic Constrictive Trigeminal Nerve Injury: Effects of Menthol and Capsazepine. Mol. Pain 2013, 9, 28.

60. Knowlton, W. M.; Palkar, R.; Lippoldt, E. K.; McCoy, D. D.; Baluch, F.; Chen, J.; McKemy, D. D. A Sensory-Labeled Line for Cold: TRPM8-Expressing Sensory Neurons Define the Cellular Basis for Cold, Cold Pain, and Cooling-Mediated Analgesia. J. Neurosci. 2013, 33, 2837-2848.

61. Caspani, O.; Zurborg, S.; Labuz, D.; Heppenstall, P. A. The Contribution of TRPM8 and TRPA1 Channels to Cold Allodynia and Neuropathic Pain. PLoS One 2009, 4, e7383.

62. Madrid, R.; de la Pena, E.; Donovan-Rodriguez, T.; Belmonte, C.; Viana, F. Variable Threshold of Trigeminal Cold-Thermosensitive Neurons is Determined by a Balance between TRPM8 and Kv1 Potassium Channels. J. Neurosci. 2009, 29, 3120-3131.

63. Noel, J.; Zimmermann, K.; Busserolles, J.; Deval, E.; Alloui, A.; Diochot, S.; Guy, N.; Borsotto, M.; Reeh, P.; Eschalier, A.; Lazdunski, M. The Mechano-Activated K+ Channels TRAAK and TREK-1 Control both Warm and Cold Perception. EMBO J. 2009, 28, 13081318.

64. Zimmermann, K.; Leffler, A.; Babes, A.; Cendan, C. M.; Carr, R. W.; Kobayashi, J.-i.; Nau, C.; Wood, J. N.; Reeh, P. W. Sensory Neuron Sodium Channel Nav1.8 is Essential for Pain atLow Temperatures. Nature 2007, 447, 855-858.

65. Lolignier, S.; Bonnet, C.; Gaudioso, C.; Noel, J.; Ruel, J.; Amsalem, M.; Ferrier, J.; Rodat-Despoix, L.; Bouvier, V.; Aissouni, Y.; Prival, L.; Chapuy, E.; Padilla, F.; Eschalier, A.; Delmas, P.; Busserolles, J. The Nav1.9 Channel Is a Key Determinant of Cold Pain Sensation and Cold Allodynia. Cell Rep. 2015, 11, 1067-1078.

66. Patel, R.; Goncalves, L.; Leveridge, M.; Mack, S. R.; Hendrick, A.; Brice, N. L.; Dickenson, A. H. Anti-hyperalgesic effects of a novel TRPM8 agonist in neuropathic rats: A comparison with topical menthol. Pain 2014, 155, 2097-2107. 
67. Descoeur, J.; Pereira, V.; Pizzoccaro, A.; Francois, A.; Ling, B.; Maffre, V.; Couette, B.; Busserolles, J.; Courteix, C.; Noel, J.; Lazdunski, M.; Eschalier, A.; Authier, N.; Bourinet, E. Oxaliplatin-Induced Cold Hypersensitivity is Due to Remodelling of Ion Channel Expression in Nociceptors. EMBO Mol. Med. 2011, 3, 266-278.

68. Su, L.; Wang, C.; Yu, Y.-H.; Ren, Y.-Y.; Xie, K.-L.; Wang, G.-L. Role of TRPM8 in Dorsal Root Ganglion in Nerve Injury-Induced Chronic Pain. BMC Neurosci. 2011, 12, 120.

69. Kono, T.; Satomi, M.; Suno, M.; Kimura, N.; Yamazaki, H.; Furukawa, H.; Matsubara, K. Oxaliplatin-Induced Neurotoxicity Involves TRPM8 in the Mechanism of Acute Hypersensitivity to Cold Sensation. Brain Behav. 2012, 2, 68-73.

70. Fallon, M. T.; Storey, D. J.; Krishan, A.; Weir, C. J.; Mitchell, R.; Fleetwood-Walker, S. M.; Scott, A. C.; Colvin, L. A. Cancer Treatment-Related Neuropathic Pain: Proof of Concept Study with Menthol-A TRPM8 Agonist. Support. Care Cancer 2015, 23, 2769-2777.

71. Colvin, L. A.; Johnson, P. R. E.; Mitchell, R.; Fleetwood-Walker, S. M.; Fallon, M. From Bench to Bedside: A Case of Rapid Reversal of Bortezomib-Induced Neuropathic Pain by the TRPM8 Activator, Menthol. J. Clin. Oncol. 2008, 26, 4519-4520.

72. Storey, D. J.; Colvin, L. A.; Mackean, M. J.; Mitchell, R.; Fleetwood-Walker, S. M.; Fallon, M. T. Reversal of Dose-Limiting Carboplatin-Induced Peripheral Neuropathy with TRPM8 Activator, Menthol, Enables Further Effective Chemotherapy Delivery. J. Pain Symptom Manag. 2010, 39, e2-e4.

73. Mukerji, G.; Yiangou, Y.; Corcoran, S. L.; Selmer, I. S.; Smith, G. D.; Benham, C. D.; Bountra, C.; Agarwal, S. K.; Anand, P. Cool and menthol receptor TRPM8 in human urinary bladder disorders and clinical correlations. BMC Urol. 2006, 6, 6.

74. Al-Hayek, S.; Abrams, P. The 50-Year History of the Ice Water Test in Urology. J. Urol. 2010, 183, 1686-1692.

75. Almeida, M. C.; Hew-Butler, T.; Soriano, R. N.; Rao, S.; Wang, W.; Wang, J.; Tamayo, N.; Oliveira, D. L.; Nucci, T. B.; Aryal, P.; Garami, A.; Bautista, D.; Gavva, N. R.; Romanovsky, A. A. Pharmacological Blockade of the Cold Receptor TRPM8 Attenuates Autonomic and 
Behavioral Cold Defenses and Decreases Deep Body Temperature. J. Neurosci. 2012, 32, 2086-2099.

76. Winchester, W. J.; Gore, K.; Glatt, S.; Petit, W.; Gardiner, J. C.; Conlon, K.; Postlethwaite, M.; Saintot, P.-P.; Roberts, S.; Gosset, J. R.; Matsuura, T.; Andrews, M. D.; Glossop, P. A.; Palmer, M. J.; Clear, N.; Collins, S.; Beaumont, K.; Reynolds, D. S. Inhibition of TRPM8 Channels Reduces Pain in the Cold Pressor Test in Humans. J. Pharmacol. Exp. Ther. 2014, 351, 259-269, 11 pp.

77. Silberstein, S. D. Migraine. Lancet 2004, 363, 381-391.

78. Oxford, G. S.; Hurley, J. H. The Role of TRP Channels in Migraine. Open Pain J. 2013, $6,37-49$.

79. Dussor, G.; Yan, J.; Xie, J. Y.; Ossipov, M. H.; Dodick, D. W.; Porreca, F. Targeting TRP Channels For Novel Migraine Therapeutics. ACS Chem. Neurosci. 2014, 5, 1085-1096.

80. Freilinger, T.; Anttila, V.; de Vries, B.; Malik, R.; Kallela, M.; Terwindt, G. M.; PozoRosich, P.; Winsvold, B.; Nyholt, D. R.; van Oosterhout, W. P. J.; Artto, V.; Todt, U.; Haemaelaeinen, E.; Fernandez-Morales, J.; Louter, M. A.; Kaunisto, M. A.; Schoenen, J.; Raitakari, O.; Lehtimaeki, T.; Vila-Pueyo, M.; Goebel, H.; Wichmann, E.; Sintas, C.; Uitterlinden, A. G.; Hofman, A.; Rivadeneira, F.; Heinze, A.; Tronvik, E.; van Duijn, C. M.; Kaprio, J.; Cormand, B.; Wessman, M.; Frants, R. R.; Meitinger, T.; Mueller-Myhsok, B.; Zwart, J.-A.; Faerkkilae, M.; Macaya, A.; Ferrari, M. D.; Kubisch, C.; Palotie, A.; Dichgans, M.; van den Maagdenberg, A. M. J. M.; International, H. G. C. Genome-wide Association Analysis Identifies Susceptibility Loci for Migraine without Aura. Nat. Genet. 2012, 44, 777-782.

81. de Vries, B.; Vijfhuizen, L. S.; Anttila, V.; Freilinger, T.; Wessman, M.; Kaunisto, M. A.; Kallela, M.; Artto, V.; Gobel, H.; Dichgans, M.; Kubisch, C.; Ferrari, M. D.; Terwindt, G. M.; Palotie, A.; van, d. M. A. M. Systematic Re-evaluation of genes from Candidate Gene Association Studies in Migraine using a Large Genome-wide Association Data Set. Cephalalgia 2015. 
82. Carreno, O.; Corominas, R.; Fernandez-Morales, J.; Camina, M.; Sobrido, M.-J.; Fernandez-Fernandez, J. M.; Pozo-Rosich, P.; Cormand, B.; Macaya, A. SNP Variants within the Vanilloid TRPV1 and TRPV3 Receptor Genes are Associated with Migraine in the Spanish Population. Am. J. Med. Genet. 2012, 159, 94-103.

83. Prevarskaya, N.; Zhang, L.; Barritt, G. TRP Channels in Cancer. BBA-Mol. Basis Dis. 2007, 1772, 937-946.

84. Bödding, M. TRP Proteins and Cancer. Cell Sig. 2007, 19, 617-624.

85. Kaneko, Y.; Szallasi, A. Transient Receptor Potential (TRP) Channels: a Clinical Perspective. Br. J. Pharmacol. 2014, 171, 2474-2507.

86. Santoni, G.; Farfariello, V. TRP Channels and Cancer: New Targets for Diagnosis and Chemotherapy. Endocr. Metab. Immune Disord. 2011, 11, 54-67.

87. Gkika, D.; Prevarskaya, N. TRP Channels in Prostate Cancer: the Good, the Bad and the Ugly? Asian J. Androl. 2011, 13, 673-6.

88. Liu, Z.; Wu, H.; Wei, Z.; Wang, X.; Shen, P.; Wang, S.; Wang, A.; Chen, W.; Lu, Y.; Wu, H.; Lu, Y. TRPM8: a Potential Target for Cancer Treatment. J. Cancer Res. Clin. Oncol. 2016.

89. Yee, N. S.; Yee, N. S.; Yee, N. S. Roles of TRPM8 Ion Channels in Cancer: Proliferation, Survival, and Invasion. Cancers 2015, 7, 2134-46.

90. Reid, G.; Flonta, M. Cold Transduction by Inhibition of a Background Potassium Conductance in Rat Primary Sensory Neurones. Neurosci. Lett. 2001, 297, 171-4.

91. Henshall, S. M.; Afar, D. E. H.; Hiller, J.; Horvath, L. G.; Quinn, D. I.; Rasiah, K. K.; Gish, K.; Willhite, D.; Kench, J. G.; Gardiner-Garden, M.; Stricker, P. D.; Scher, H. I.; Grygiel, J. J.; Agus, D. B.; Mack, D. H.; Sutherland, R. L. Survival Analysis of Genome-Wide Gene Expression Profiles of Prostate Cancers Identifies New Prognostic Targets of Disease Relapse. Cancer Res. 2003, 63, 4196-4203.

92. Zhang, L.; Barritt, G. J. Evidence that TRPM8 Is an Androgen-Dependent Ca2+ Channel Required for the Survival of Prostate Cancer Cells. Cancer Res. 2004, 64, 83658373. 
93. Bidaux, G.; Roudbaraki, M.; Merle, C.; Crépin, A.; Delcourt, P.; Slomianny, C.; Thebault, S.; Bonnal, J.-L.; Benahmed, M.; Cabon, F.; Mauroy, B.; Prevarskaya, N. Evidence for Specific TRPM8 Expression in Human Prostate Secretory Epithelial Cells: Functional Androgen Receptor Requirement. Endocr. Relat. Cancer 2005, 12, 367-382.

94. Thebault, S.; Lemonnier, L.; Bidaux, G.; Flourakis, M.; Bavencoffe, A.; Gordienko, D. Novel Role of Cold/Menthol-Sensitive Transient Receptor Potential Melastatine Family Member 8 (TRPM8) in the Activation of Store-Operated Channels in LNCaP Human Prostate Cancer Epithelial Cells. J. Biol. Chem. 2005, 280, 39423-39435.

95. Bidaux, G.; Flourakis, M.; Thebault, S.; Zholos, A.; Beck, B.; Gkika, D.; Roudbaraki, M.; Bonnal, J.-L.; Mauroy, B.; Shuba, Y.; Skryma, R.; Prevarskaya, N. Prostate Cell Differentiation Status Determines Transient Receptor Potential Melastatin Member 8 Channel Subcellular Localization and Function. J. Clin. Invest. 2007, 117, 1647-1657.

96. Hendriksen, P. J. M.; Dits, N. F. J.; Kokame, K.; Veldhoven, A.; van Weerden, W. M.; Bangma, C. H.; Trapman, J.; Jenster, G. Evolution of the Androgen Receptor Pathway during Progression of Prostate Cancer. Cancer Res. 2006, 66, 5012-5020.

97. Zhu, G.; Wang, X.; Yang, Z., Cao, H., ; Meng, Z., Wang, Y., ; Chen, D. Effects of TRPM8 on the Proliferation and Angiogenesis of Prostate Cancer PC-3 Cells In vivo. Oncol. Lett. 2011, 2, 1213-1217.

98. Valero, M. L.; Mello de Queiroz, F.; Stuehmer, W.; Viana, F.; Pardo, L. A. TRPM8 Ion Channels Differentially Modulate Proliferation and Cell Cycle Distribution of Normal and Cancer Prostate Cells. PLoS One 2012, 7, e51825.

99. Hamdy, F. C. Prognostic and Predictive Factors in Prostate Cancer. Cancer Treat. Rev. 2001, 27, 143-151.

100. Fuessel, S.; Sickert, D.; Meye, A.; Klenk, U.; Schmidt, U.; Schmitz, M.; Rost, A.-K.; Weigle, B.; Kiessling, A.; Wirth, M. P. Multiple Tumor Marker Analyses (PSA, hK2, PSCA, trp-p8) in Primary Prostate Cancers Using Quantitative RT-PCR. Int. J. Oncol. 2003, 23, 221-8. 
101. Bai, V. U.; Murthy, S.; Chinnakannu, K.; Muhletaler, F.; Tejwani, S.; Barrack, E. R.; H., K. S.; Menon, M.; Veer Reddy, G. P. Androgen Regulated TRPM8 Expression: A Potential mRNA Marker for Metastatic Prostate Cancer Detection in Body Fluids. Int. J. Oncol. 2010, $36,443$.

102. Chodon, D.; Guilbert, A.; Dhennin-Duthille, I.; Gautier, M.; Telliez, M.-S.; Sevestre, H.; Ouadid-Ahidouch, H. Estrogen Regulation of TRPM8 Expression in Breast Cancer Cells. BMC Cancer 2010, 10, 212.

103. Okamoto, Y.; Ohkubo, T.; Ikebe, T.; Yamazaki, J. Blockade of TRPM8 Activity Reduces the Invasion Potential of Oral Squamous Carcinoma Cell Lines. Int. J. Oncol. 2012, $40,1431-1440$.

104. Yee, N. S.; Zhou, W.; Lee, M. Transient Receptor Potential Channel TRPM8 is OverExpressed and Required for Cellular Proliferation in Pancreatic Adenocarcinoma. Cancer Lett. 2010, 297, 49-55.

105. Yee, N. S.; Brown, R. D.; Lee, M. S.; Zhou, W.; Jensen, C.; Gerke, H.; Yee, R. K. TRPM8 Ion Channel is Aberrantly Expressed and Required for Preventing Replicative Senescence in Pancreatic Adenocarcinoma: Potential Role of TRPM8 as a Biomarker and Target. Cancer Biol. Ther. 2012, 13, 592-599.

106. Willis, D. N.; Liu, B.; Ha, M. A.; Jordt, S.-E.; Morris, J. B. Menthol Attenuates Respiratory Irritation Responses to Multiple Cigarette Smoke Irritants. FASEB J. 2011, 25, 4434-4444.

107. Xing, H.; Ling, J. X.; Chen, M.; Johnson, R. D.; Tominaga, M.; Wang, C.-Y.; Gu, J. TRPM8 Mechanism of Autonomic Nerve Response to Cold in Respiratory Airway. Mol. Pain 2008, 4, 22-22.

108. Naumov, D. E.; Perelman, J. M.; Kolosov, V. P.; Potapova, T. A.; Maksimov, V. N.; Zhou, X. Transient Receptor Potential Melastatin 8 Gene Polymorphism is Associated with Cold-Induced Airway Hyperresponsiveness in Bronchial Asthma. Respirology 2015, 20, 1192-1197. 
109. Franken, J.; Uvin, P.; De Ridder, D.; Voets, T. TRP Channels in Lower Urinary Tract Dysfunction. Br. J. Pharmacol. 2014, 171, 2537-2551.

110. Lei, Z.; Ishizuka, O.; Imamura, T.; Noguchi, W.; Yamagishi, T.; Yokoyama, H.; Kurizaki, Y.; Sudha, G. S.; Hosoda, T.; Nishizawa, O.; Andersson, K.-E. Functional Roles of Transient Receptor Potential Melastatin 8 (TRPM8) Channels in the Cold Stress-Induced Detrusor Overactivity Pathways in Conscious Rats. Neurourol. Urodyn. 2013, 32, 500-504. 111. Mukerji, G.; Yiangou, Y.; Corcoran, S. L.; Selmer, I. S.; Smith, G. D.; Benham, C. D.; Bountra, C.; Agarwal, S. K.; Anand, P. Cool and Menthol Receptor TRPM8 in Human Urinary Bladder Disorders and Clinical Correlations. BMC Urol. 2006, 6, 6.

112. Ma, S.; Yu, H.; Zhao, Z.; Luo, Z.; Chen, J.; Ni, Y.; Jin, R.; Ma, L.; Wang, P.; Zhu, Z.; Li, L.; Zhong, J.; Liu, D.; Nilius, B.; Zhu, Z. Activation of the Cold-Sensing TRPM8 Channel Triggers UCP1-Dependent Thermogenesis and Prevents Obesity. J. Molecular Cell Biol. 2012, 4, 8896.

113. Rossato, M.; Granzotto, M.; Macchi, V.; Porzionato, A.; Petrelli, L.; Calcagno, A.; Vencato, J.; De Stefani, D.; Silvestrin, V.; Rizzuto, R.; Bassetto, F.; De Caro, R.; Vettor, R. Human White Adipocytes Express the Cold Receptor TRPM8 which Activation Induces UCP1 Expression, Mitochondrial Activation and Heat Production. Mol. Cell. Endocr. 2014, $383,137-146$.

114. Tabur, S.; Oztuzcu, S.; Duzen, I. V.; Eraydin, A.; Eroglu, S.; Ozkaya, M.; Demiryürek, A. T. Role of the Transient Receptor Potential (TRP) Channel Gene Expressions and TRP Melastatin (TRPM) Channel Gene Polymorphisms in Obesity-Related Metabolic Syndrome. Eur. Rev. Med. Pharm. Sci. 2015, 19, 1388-1397.

115. Zholos, A. Pharmacology of Transient Receptor Potential Melastatin Channels in the Vasculature. Br. J. Pharmacol. 2010, 159, 1559-1571.

116. Yang, X.-R.; Lin, M.-J.; McIntosh, L. S.; Sham, J. S. K. Functional Expression of Transient Receptor Potential Melastatin- and Vanilloid-Related Channels in Pulmonary Arterial and Aortic Smooth Muscle. Am. J. Physiol. 2006, 290, L1267-L1276. 
117. Liu, X. R.; Liu, Q.; Chen, G. Y.; Hu, Y.; Sham, J. S. K.; Lin, M. J. Down-Regulation of TRPM8 in Pulmonary Arteries of Pulmonary Hypertensive Rats. Cell. Physiol. Biochem. 2013, 31, 892-904.

118. Sun, J.; Yang, T.; Wang, P.; Ma, S.; Zhu, Z.; Pu, Y.; Li, L.; Zhao, Y.; Xiong, S.; Liu, D.; Zhu,

Z. Activation of Cold-Sensing Transient Receptor Potential Melastatin Subtype 8 Antagonizes Vasoconstriction and Hypertension Through Attenuating RhoA/Rho Kinase Pathway. Hypertension 2014, 63, 1354-1363.

119. Silva, D. F.; Moura de Almeida, M.; Chaves, C. G.; Braz, A. L.; Gomes, M. A.; Pinho-daSilva, L.; Pesquero, J. L.; Andrade, V. A.; Leite, M. d. F.; Ferreira de Albuquerque, J. G.; Araujo, I. G. A.; Nunes, X. P.; Barbosa-Filho, J. M.; dos Santos Cruz, J.; Correia, N. d. A.; Almeida de Medeiros, I. TRPM8 Channel Activation Induced by Monoterpenoid Rotundifolone Underlies Mesenteric Artery Relaxation. PLoS One 2015, 10, e0143171.

120. Parra, A.; Madrid, R.; Echevarria, D.; del Olmo, S.; Morenilla-Palao, C.; Acosta, C. M.; Gallar, J.; Dhaka, A.; Viana, F.; Belmonte, C. Ocular Surface Wetness is Regulated by TRPM8Dependent Cold Thermoreceptors of the Cornea. Nat. Med. 2010, 16, 1396-1399.

121. Quallo, T.; Vastani, N.; Horridge, E.; Gentry, C.; Moss, S.; Andersson, D. A.; Bevan, S.; Parra, A.; Viana, F.; Belmonte, C. TRPM8 is a Neuronal Osmosensor that Regulates Eye Blinking in Mice. Nat. Commun. 2015, 6, 7150.

122. Szychowski, J.; Truchon, J.-F.; Bennani, Y. L. Natural Products in Medicine: Transformational Outcome of Synthetic Chemistry. J. Med. Chem. 2014, 57, 9292-9308.

123. Szallasi, A.; Di Marzo, V. New Perspectives on Enigmatic Vanilloid Receptors. Trends Neurosci. 2000, 23, 491-497.

124. Behrendt, H. J.; Germann, T.; Gillen, C.; Hatt, H.; Jostock, R. Characterization of the Mouse Cold-Menthol Receptor TRPM8 and Vanilloid Receptor Type-1 VR1 Using a Fluorometric Imaging Plate Reader (FLIPR) Assay. Br. J. Pharmacol. 2004, 141, 737-745.

125. Wei, E. T. N-(Substituted-aryl-alkyl)-cycloalkyl carboxamide compositions and use in treating skin and sensory disorders. US20050187211A1, 2005. 
126. Beck, B.; Bidaux, G.; Bavencoffe, A.; Lemonnier, L.; Thebault, S.; Shuba, Y.; Barrit, G.; Skryma, R.; Prevarskaya, N. Prospects for Prostate Cancer Imaging and Therapy Using High-Affinity TRPM8 Activators. Cell Calcium 2007, 41, 285-294.

127. Wei, E. T. Radioligands for the trp-m8 receptor and methods therewith. US20050084447A1, 2005.

128. Sherkheli, M. A.; Vogt-Eisele, A. K.; Bura, D.; Marques, L. R. B.; Gisselmann, G.; Hatt, H. Characterization of Selective TRPM8 Ligands and their Structure Activity Response (SAR) Relationship. J. Pharm. Pharmaceu. Sci. 2010, 13, 242-253.

129. Moreno, O.; Natarajan, S.; Duncan, D. F. Small-Molecule Modulators of Trp-p8 Activity. W02009067410A1, 2009.

130. Haught, J. C.; Reilly, M.; Hoke, S. H.; Lei, Q.; Lin, Y.; Sreekrishna, K. T.; Traboulsi, A. Cyclohexanecarboxamide with cooling properties. W02015164553A1, 2015.

131. Tolcher, A. W.; Patnaik, A.; Papadopoulos, K.; Mays, T.; Stephan, T. E.; Humble, D. J.; Frohlich, M. W.; B., S. R. Preliminary Results from a Phase 1 Study of D-3263 HCl, a TRPM8 Calcium Channel Agonist, in Patients with Advanced Cancer. In 2010; p file:///M:/TRABAJOS/TRPM8\%20review\%20JMC/DD3263.pdf.

132. Shirai, T.; Kumihashi, K. Preparation of menthol derivatives as cooling agents and TRPM8 activators. JP2014227390A, 2014.

133. Chumakova, L.; Patron, A.; Priest, C.; Karanewsky, D. S.; Kimmich, R.; Boren, B. C.; Hammaker, J. R.; Chumakov, V.; Zhao, W.; Noncovich, A.; Ung, J. Compounds Useful as Modulators of TRPM8. WO2014130582A2, 2014.

134. Fleetwood-Walker, S.; Mitchell, R.; Proudfoot, C. W. J. Induction of analgesia in neuropathic pain. WO2008015403A1, 2008.

135. Kijpornyongpan, T.; Sereemaspun, A.; Chanchao, C. Dose-Dependent Cytotoxic Effects of Menthol on Human Malignant Melanoma A-375 Cells: Correlation with TRPM8 Transcript Expression. Asian Pac. J. Cancer Prev. 2014, 15, 1551-6. 
136. Li, Q.; Wang, X.; Yang, Z.; Wang, B.; Li, S. Menthol Induces Cell Death via the TRPM8 Channel in the Human Bladder Cancer Cell Line T24. Oncology 2009, 77, 335-341.

137. Belmonte Martinez, C.; Gallar Martinez, J.; Ferrer Montiel, A.; Fernandez Carvajal, A.; Viana de la Iglesia, F. Pharmaceutical composition for the treatment of dry eye. W02012032209A2, 2012.

138. Bharate, S. S.; Bharate, S. B. Modulation of Thermoreceptor TRPM8 by Cooling Compounds. Acs Chemical Neuroscience 2012, 3, 248-267.

139. Andersson, D. A.; Chase, H. W. N.; Bevan, S. TRPM8 Activation by Menthol, Icilin, and Cold is Differentially Modulated by Intracellular pH. J. Neurosci. 2004, 24, 5364-5369. 140. Sherkheli, M. A.; Gisselmann, G.; Hatt, H. Supercooling Agent Icilin Blocks a Warmth-Sensing Ion Channel TRPV3. Sci. World J. 2012, 2012, 982725.

141. Brignell, J. L.; Chapman, V.; Kendall, D. A. Comparison of Icilin- and Cold-Evoked Responses of Spinal Neurones, and their Modulation of Mechanical Activity, in a Model of Beuropathic Pain. Brain Res. 2008, 1215, 87-96.

142. Anand, U.; Otto, W. R.; Anand, P. Sensitization of Capsaicin and Icilin Responses in Oxaliplatin Treated Adult Rat DRG Neurons. Mol. Pain 2010, 6, 82.

143. Hagenacker, T.; Lampe, M.; Schaefers, M. Icilin Reduces Voltage-Gated Calcium Channel Currents in Naive and Injured DRG Neurons in the Rat Spinal Nerve Ligation Model. Brain Res. 2014, 1557, 171-179.

144. Camacho, S.; Michlig Gonzalez, S.; Le Coutre, J.; Markram, H.; Pezzoli, M. Treatment or prevention of neurodegenerative disorders using menthol, linalool and/or icilin. W02014187942A1, W02014187946A1, 2014.

145. Lee, S.; Chun, J. N.; Kim, S.-H.; So, I.; Jeon, J.-H. Icilin Inhibits E2F1-Mediated Cell Cycle Regulatory Programs in Prostate Cancer. Biochem. Biophys. Res. Commun. 2013, 441, $1005-1010$. 
146. De Petrocellis, L.; Ortar, G.; Moriello, A. S.; Serum, E. M.; Rusterholz, D. B. StructureActivity Relationships of the Prototypical TRPM8 Agonist Icilin. Bioorg. Med. Chem. Lett. 2015, 25, 2285-2290.

147. Surburg, H.; Backes, M.; Oertling, H.; Machinek, A.; Loges, H.; Simchen, U.; Subkowski, T.; Bollscheiler, C.; Wittenberg, J.; Siegel, W. Use of Physiological Cooling Active Ingredients and Agents Containing such Active Ingredients. WO2011061330A2, 2011.

148. Ostacolo, C.; Ambrosino, P.; Russo, R.; Lo Monte, M.; Soldovieri, M. V.; Laneri, S.; Sacchi, A.; Vistoli, G.; Taglialatela, M.; Calignano, A. Isoxazole Derivatives as Potent Transient Receptor Potential Melastatin Type 8 (TRPM8) Agonists. Eur. J. Med. Chem. 2013, 69, 659-669.

149. Jiang, T.; Sui, F.; Huo, H.; Li, L.; Guo, S. New use of neferine. W02010118675A1, 2010.

150. Selescu, T.; Ciobanu, A. C.; Dobre, C.; Reid, G.; Babes, A. Camphor Activates and Sensitizes Transient Receptor Potential Melastatin 8 (TRPM8) to Cooling and Icilin. Chem. Senses 2013, 38, 563-575.

151. Ottinger, H.; Soldo, T.; Hofmann, T. Systematic Studies on Structure and Physiological Activity of Cyclic Alpha-Keto Enamines, a Novel Class of "Cooling" Compounds. J. Agr. Food Chem. 2001, 49, 5383-5390.

152. Bassoli, A.; Borgonovo, G.; Busnelli, G.; Morini, G. Synthesis of a New Family of NAryl Lactams Active on Chemesthesis and Taste. Eur. J. Org. Chem. 2006, 2006, 1656-1663. 153. Takaishi, M.; Fujita, F.; Uchida, K.; Yamamoto, S.; Sawada, M.; Hatai, C.; Shimizu, M.; Tominaga, M. 1,8-Cineole, a TRPM8 Agonist, is a Novel Natural Antagonist of Human TRPA1. Mol. Pain 2012, 8, 86.

154. Subkowski, T.; Bollschweiler, C.; Wittenberg, J.; Krohn, M.; Zinke, H. Detection and use of low-molecular weight modulators of the cold-menthol receptor TRPM8. W02010026094A1, 2010. 
155. Wei, E. T. Di-isopropyl-phosphinoyl Alkane (DIPA) Compounds as Topical Agent for the Treatment of Sensory Discomfort. W02015059432A1, 2015.

156. Boedding, M.; Wissenbach, U.; Flockerzi, V. Characterisation of TRPM8 as a Pharmacophore Receptor. Cell Calcium 2007, 42, 618-628.

157. Bertamino, A.; Ostacolo, C.; Ambrosino, P.; Musella, S.; Di Sarno, V.; Ciaglia, T.; Soldovieri, M. V.; Iraci, N.; Fernandez Carvajal, A.; de la Torre-Martínez, R.; Ferrer-Montiel, A.; Gonzalez Muniz, R.; Novellino, E.; Taglialatela, M.; Campiglia, P.; Gomez-Monterrey, I. Tryptamine-Based Derivatives as Transient Receptor Potential Melastatin Type-8 (TRPM8) Channel Modulators J. Med. Chem. 2016, 59, 2179-2191.

158. Branum, S. T.; Colburn, R. W.; Dax, S. L.; Flores, C. M.; Jetter, M. C.; Liu, Y.; Ludovici, D.; Macielag, M. J.; Matthews, J. M.; McNally, J. J.; Reaney, L. M.; Russell, R. K.; Qin, N.; Wells, K. M.; Youells, S. C.; Youngman, M. A. Sulfonamides as TRPM8 Modulators. WO2009012430A1, 2009.

159. Acton, P. D.; Hlasta, D. J.; Matthews, J. M.; McNally, J. J. Radiolabelled TRPM8 receptor ligands. W02010009220A2, 2010.

160. Macielag, M. J.; McNally, J. J. Sulfonamides as TRPM8 Modulators. US20100160289A1, 2010.

161. Matthews, J. M. Sulfamides as TRPM8 Modulators. US20100160337A1, 2010.

162. Colburn, R. W.; Dax, S. L.; Flores, C.; Matthews, J. Cold menthol receptor-1 antagonists. US20120053347A1, 2012.

163. Matthews, J. M.; Qin, N.; Colburn, R. W.; Dax, S. L.; Hawkins, M.; McNally, J. J.; Reany, L.; Youngman, M. A.; Baker, J.; Hutchinson, T.; Liu, Y.; Lubin, M. L.; Neeper, M.; Brandt, M. R.; Stone, D. J.; Flores, C. M. The Design and Synthesis of Novel, Phosphonate-Containing Transient Receptor Potential Melastatin 8 (TRPM8) Antagonists. Bioorg. Med. Chem. Lett. 2012, 22, 2922-2926.

164. Macielag, M. J.; Xia, M.; Xu, X. Benzimidazole derivatives useful as TRPM8 receptor modulators. WO2010144679A1, 2010. 
165. Jetter, M. C.; Macielag, M. J.; Xia, M.; Xu, X. Benzimidazole derivatives useful as TRPM8 receptor modulators. W02010144680A1, 2010.

166. Calvo, R. R.; Meegalla, S. K.; Player, M. R. Benzimidazole Derivatives Useful as TRPM8 Receptor Modulators. WO2010132247A1, 2010.

167. Calvo, R. R.; Meegalla, S. K.; Parks, D. J.; Parsons, W. H.; Ballentine, S. K.; Lubin, M. L.; Schneider, C.; Colburn, R. W.; Flores, C. M.; Player, M. R. Discovery of VinylcycloalkylSubstituted Benzimidazole TRPM8 Antagonists Effective in the Treatment of Cold Allodynia. Bioorg. Med. Chem. Lett. 2012, 22, 1903-1907.

168. Player, M. R.; Parks, D. J.; Parsons, W.; Meegalla, S. K.; Illig, C. R.; Ballentine, S. K. Heterocyclic benzimidazoles as TRPM8 modulators. US20100093788A1, 2010.

169. Player, M. R.; Calvo, R.; Chen, J.; Meegalla, S.; Parks, D.; Parsons, W.; Ballentine, S.; Branum, S. Sunstituted aza-bicyclic imidazole derivatives useful as TRPM8 receptor modulators. US20110218197A1, 2011.

170. Inoue, T.; Ohmi, M.; Kawamura, K.; Ando, K.; Shishido, Y. Sulfamoyl benzoic acid derivatives as TRPM8 antagonists. W02010125831A1, 2010.

171. Kawamura, K.; Shishido, Y.; Ohmi, M. Sulfamoyl Benzoic Acid Heterobicyclic Derivatives as TRPM8 Antagonists. WO2012042915A1, 2012.

172. Ohmi, M.; Shishido, Y.; Inoue, T.; Ando, K.; Fujiuchi, A.; Yamada, A.; Watanabe, S.; Kawamura, K. Identification of a Novel 2-Pyridyl-benzensulfonamide Derivative, RQ00203078, as a Selective and Orally Active TRPM8 Antagonist. Bioorg. Med. Chem. Lett. 2014, 24, 5364-5368.

173. Kato, T.; Sakamoto, T.; Kubo, A.; Sawamoto, D. Sulfonamide compounds. W02014042238A1, 2014.

174. Irlapati, N. R.; Thomas, A.; Kurhe, D. K.; Shelke, S. Y.; Khairatkar, J. N.; Viswanadha, S.; Mukhopadhyay, I. Fused Oxazole and Thiazole Derivatives as TRPM8 Modulators. W02010010435A2, 2010. 
175. Norman, M. H.; Bo, Y. Y.; Gore, V. K.; Horne, D.; Kaller, M.; Ma, V. V.; Monenschein, H.; Nguyen, T.; Nishimura, N.; Tamayo, N. TRP-M8 receptor ligands and their use in treatments. WO2009073203A1, 2009.

176. Nishimura, N.; Norman, M. H.; Tamayo, N.; Tang, P.; Bo, Y. Y. Condensed piperidine derivatives useful as vanilloid receptor ligands. W02009038812A1, 2009.

177. Tamayo, N. A.; Bo, Y.; Gore, V.; Ma, V.; Nishimura, N.; Tang, P.; Deng, H.; Klionsky, L.; Lehto, S. G.; Wang, W.; Youngblood, B.; Chen, J.; Correll, T. L.; Bartberger, M. D.; Gavva, N. R.; Norman, M. H. Fused Piperidines as a Novel Class of Potent and Orally Available Transient Receptor Potential Melastatin Type 8 (TRPM8) Antagonists. J. Med. Chem. 2012, 55, 15931611.

178. Horne, D. B.; Tamayo, N. A.; Bartberger, M. D.; Bo, Y.; Clarine, J.; Davis, C. D.; Gore, V. K.; Kaller, M. R.; Lehto, S. G.; Ma, V. V.; Nishimura, N.; Nguyen, T. T.; Tang, P.; Wang, W.; Youngblood, B. D.; Zhang, M.; Gavva, N. R.; Monenschein, H.; Norman, M. H. Optimization of Potency and Pharmacokinetic Properties of Tetrahydroisoquinoline Transient Receptor Potential Melastatin 8 (TRPM8) Antagonists. J. Med. Chem. 2014, 57, 2989-3004.

179. Chaudhari, S. S.; Thomas, A.; Kadam, A. B.; Adik, B. G.; Dhone, S. V.; Khairatkar-Joshi, N.; Mukhopadhyay, I. Spirocyclic piperidine derivatives as TRP8 modulators. W02010103381A1, 2010.

180. Chaudhari, S. S.; Kadam, A. B.; Khairatkar-Joshi, N.; Mukhopadhyay, I.; Karnik, P. V.; Raghuram, A.; Rao, S. S.; Vaiyapuri, T. S.; Wale, D. P.; Bhosale, V. M.; Gudi, G. S.; Sangana, R. R.; Thomas, A. Synthesis and Pharmacological Evaluation of Novel N-Aryl-3,4-dihydro-1' H-spiro chromene-2,4'-piperidine -1'-carboxamides as TRPM8 Antagonists. Bioorg. Med. Chem. 2013, 21, 6542-6553.

181. Lampe, T.; Alonso-Alija, C.; Beck, H.; Rosentreter, U.; Sandner, P.; Stahl, E.; StelteLudwig, B. Substituted benzyloxy-phenylmethylurea derivatives, processes for preparing them, pharmaceutical compositions containing them, and their use as CMR-1 (Cold Menthol Receptor 1) antagonists. W02007080109A1, 2007. 
182. Colburn, R. W.; Dax, S. L.; Flores, C. M.; Ludovici, D. W.; Mathews, J. M.; Xia, M.; Xu, X.; Youngman, M. A.; Zhu, B. Cold menthol receptor antagonists. WO2010021878A1, 2010. 183. Zhu, B.; Xia, M.; Xu, X.; Ludovici, D. W.; Tennakoon, M.; Youngman, M. A.; Matthews, J. M.; Dax, S. L.; Colburn, R. W.; Qin, N.; Hutchinson, T. L.; Lubin, M. L.; Brandt, M. R.; Stone, D. J.; Flores, C. M.; Macielag, M. J. Arylglycine Derivatives as Potent Transient Receptor Potential Melastatin 8 (TRPM8) Antagonists. Bioorg. Med. Chem. Lett. 2013, 23, 22342237.

184. Hirasawa, H.; Kawamura, N.; Kobayashi, J. A-Substituted glycineamide derivative. W02014181788A1, 2014.

185. Hirasawa, H.; Kawamura, N.; Kobayashi, J.; Ozawa, T. a-Substituted glycinamide derivative. WO2015108136A1, 2015.

186. DeFalco, J.; Steiger, D.; Dourado, M.; Emerling, D.; Duncton, M. A. J. 5Benzyloxytryptamine as an Antagonist of TRPM8. Bioorg. Med. Chem. Lett. 2010, 20, 70767079.

187. Boess, F. G.; Monsma, F. J.; Carolo, C.; Meyer, V.; Rudler, A.; Zwingelstein, C.; Sleight, A. J. Functional and Radioligand Binding Characterization of Rat 5-HT6 Receptors Stably Expressed in HEK293 Cells. Neuropharmacology 1997, 36, 713-720.

188. Terada, Y.; Horie, S.; Takayama, H.; Uchida, K.; Tominaga, M.; Watanabe, T. Activation and Inhibition of Thermosensitive TRP Channels by Voacangine, an Alkaloid Present in Voacanga africana, an African Tree. J. Nat. Prod. 2014, 77, 285-297.

189. Lampe, T.; Alonso-Alija, C.; Beck, H.; Rosentreter, U.; Sandner, P.; Stahl, E.; StelteLudwig, B. Substituted 2-Benzyloxy-Benzoic Acid Amide Derivatives. W02007017093A1, 2007.

190. Lashinger, E. S. R.; Steiginga, M. S.; Hieble, J. P.; Leon, L. A.; Gardner, S. D.; Nagilla, R.; Davenport, E. A.; Hoffman, B. E.; Laping, N. J.; Su, X. AMTB, a TRPM8 Channel Blocker: Evidence in Rats for Activity in Overactive Bladder and Painful Bladder Syndrome. Am. J. Physiol.-Renal Physiol. 2008, 295, F803-F810. 
191. Brown, A.; Ellis, D.; Favor, D. A.; Kirkup, T.; Klute, W.; MacKenny, M.; McMurray, G.; Stennett, A. Serendipity in Drug-Discovery: A New Series of 2-(Benzyloxy)benzamides as TRPM8 Antagonists. Bioorg. Med. Chem. Lett. 2013, 23, 6118-6122.

192. Andrews, M. D.; af Forselles, K.; Beaumont, K.; Galan, S. R. G.; Glossop, P. A.; Grenie, M.; Jessiman, A.; Kenyon, A. S.; Lunn, G.; Maw, G.; Owen, R. M.; Pryde, D. C.; Roberts, D.; Thien Duc, T. Discovery of a Selective TRPM8 Antagonist with Clinical Efficacy in ColdRelated Pain. ACS Med. Chem. Lett. 2015, 6, 419-424.

193. Shishido, Y.; Ohmi, M.; Ando, K. Azaspiro derivatives as TRPM8 antagonists. W02015136947A1, 2015.

194. Moriconi, A.; Bianchini, G.; Colagioia, S.; Brandolini, L.; Aramini, A.; Liberati, C.; Bovolenta, S. TRPM8 antagonists. WO2013092711A1, 2013.

195. Mistretta, F. A.; Russo, A.; Castiglione, F.; Bettiga, A.; Colciago, G.; Montorsi, F.; Brandolini, L.; Aramini, A.; Bianchini, G.; Allegretti, M.; Bovolenta, S.; Russo, R.; Benigni, F.; Hedlund, P. DFL23448, A Novel Transient Receptor Potential Melastin 8-Selective Ion Channel Antagonist, Modifies Bladder Function and Reduces Bladder Overactivity in Awake Rats. J. Pharmacol. Exp.Ther. 2016, 356, 200-211.

196. Ortar, G.; Petrocellis, L. D.; Morera, L.; Moriello, A. S.; Orlando, P.; Morera, E.; Nalli, M.; Marzo, V. D. (-)-Menthylamine Derivatives as Potent and Selective Antagonists of Transient Receptor Potential Melastatin Type-8 (TRPM8) Channels. Bioorg. Med. Chem. Lett. 2010, 20, 2729-2732.

197. Biswas, K.; Brown, J.; Chen, J. J.; Gore, V. K.; Harried, S.; Horne, D. B.; Kaller, M. R.; Ma, V. V.; Nguyen, T. T.; Sham, K.; Zhong, W. Chroman derivatives as TRPM8 inhibitors and their preparation. W02014025651A1, 2014.

198. Pérez-Faginas, P.; Aranda, M. T.; de la Torre-Martínez, R.; Quirce, S.; FernándezCarvajal, A.; Ferrer-Montiel, A.; González-Muñiz, R. New Transient Receptor Potential TRPV1, TRPM8 and TRPA1 Channel Antagonists from a Single Linear $\beta, \gamma$-Diamino Ester Scaffold. RSC Adv. 2016, 6, 6868-6877. 
199. Ortar, G.; Schiano Moriello, A.; Morera, E.; Nalli, M.; Di Marzo, V.; De Petrocellis, L. 3Ylidenephthalides as a New Nlass of Transient Receptor Potential Channel TRPA1 and TRPM8 Modulators. Bioorg. Med. Chem. Lett. 2013, 23, 5614-5618.

200. Meseguer, V.; Karashima, Y.; Talavera, K.; D'Hoedt, D.; Donovan-Rodriguez, T.; Viana, F.; Nilius, B.; Voets, T. Transient Receptor Potential Channels in Sensory Neurons are Targets of the Antimycotic agent Clotrimazole. J. Neurosci. 2008, 28, 576-586.

201. Malkia, A.; Pertusa, M.; Fernandez-Ballester, G.; Ferrer-Montiel, A.; Viana, F. Differential Role of the Menthol-Binding Residue Y745 in the Antagonism of Thermally Gated TRPM8 Channels. Mol. Pain 2009, 5, 62.

202. Merritt, J. E.; Armstrong, W. P.; Benham, C. D.; Hallam, T. J.; Jacob, R.; Jaxa-Chamiec, A.; Leigh, B. K.; McCarthy, S. A.; Moores, K. E.; Rink, T. J. SK\&F 96365, a Novel Inhibitor of Receptor-Mediated Calcium Entry. Biochem. J. 1990, 271, 515-522.

203. De Petrocellis, L.; Starowicz, K.; Moriello, A. S.; Vivese, M.; Orlando, P.; Di Marzo, V. Regulation of Transient Receptor Potential Channels of Melastatin Type 8 (TRPM8): Effect of cAMP, Cannabinoid CB, Receptors and Endovanilloids. Exp. Cell Res. 2007, 313, 19111920.

204. Huang, S. M.; Bisogno, T.; Trevisani, M.; Al-Hayani, A.; De Petrocellis, L.; Fezza, F.; Tognetto, M.; Petros, T. J.; Krey, J. F.; Chu, C. J.; Miller, J. D.; Davies, S. N.; Geppetti, P.; Walker, J. M.; Di Marzo, V. An Endogenous Capsaicin-Like Substance with High Potency at Recombinant and Native Vanilloid VR1 Receptors. Proc. Natl. Acad. Sci. U. S. A. 2002, 99, 8400-8405.

205. De Petrocellis, L.; Ligresti, A.; Moriello, A. S.; Allara, M.; Bisogno, T.; Petrosino, S.; Stott, C. G.; Di Marzo, V. Effects of Cannabinoids and Cannabinoid-Enriched Cannabis Extracts on TRP Channels and Endocannabinoid Metabolic Enzymes. Br. J. Pharmacol. 2011, 163, 1479-1494.

206. Borrelli, F.; Pagano, E.; Romano, B.; Panzera, S.; Izzo, A. A.; Maiello, F.; Coppola, D.; De, P. L.; Buono, L.; Orlando, P. Colon Carcinogenesis is Inhibited by the TRPM8 Antagonist 
Cannabigerol, a Cannabis-Derived non-Psychotropic Cannabinoid. Carcinogenesis 2014, $35,2787-97$.

207. Sharma, M.; Hudson, J. B.; Adomat, H.; Guns, E.; Cox, M. E. In vitro Anticancer Activity of Plant-Derived Cannabidiol on Prostate Cancer Cell Lines. Pharmacol. Pharm. 2014, 5, 806-820, 16 pp.

208. Chianese, G.; Fattorusso, E.; Putra, M. Y.; Calcinai, B.; Bavestrello, G.; Moriello, A. S.; De Petrocellis, L.; Di Marzo, V.; Taglialatela-Scafati, O. Leucettamols, Bifunctionalized Marine Sphingoids, Act as Modulators of TRPA1 and TRPM8 Channels. Mar. Drugs 2012, $10,2435-2447$.

209. Ortar, G.; Moriello, A. S.; Morera, E.; Nalli, M.; Di Marzo, V.; De Petrocellis, L. Effect of Acyclic Monoterpene Alcohols and their Derivatives on TRP Channels. Bioorg. Med. Chem. Lett. 2014, 24, 5507-5511.

210. Ortar, G.; Morera, L.; Moriello, A. S.; Morera, E.; Nalli, M.; Di Marzo, V.; De Petrocellis, L. Modulation of Thermo-Transient Receptor Potential (Thermo-TRP) Channels by Thymol-Based Compounds. Bioorg. Med. Chem. Lett. 2012, 22, 3535-3539.

211. Phelps, C. B.; Gaudet, R. The Role of the N Terminus and Transmembrane Domain of TRPM8 in Channel Localization and Tetramerization. J. Biol. Chem. 2007, 282, 3647436480.

212. Tsuruda, P. R.; Julius, D.; Minor, D. L., Jr. Coiled Coils Direct Assembly of a ColdActivated TRP Channel. Neuron 2006, 51, 201-212.

213. Kuehn, F. J. P.; Knop, G.; Lueckhoff, A. The Transmembrane Segment S6 Determines Cation versus Anion Selectivity of TRPM2 and TRPM8. J. Biol. Chem. 2007, 282, 2759827609

214. Pertusa, M.; Gonzalez, A.; Hardy, P.; Madrid, R.; Viana, F. Bidirectional Modulation of Thermal and Chemical Sensitivity of TRPM8 Channels by the Initial Region of the NTerminal Domain. J. Biol. Chem. 2014, 289, 21828-21843. 
215. Stewart, A. P.; Egressy, K.; Lim, A.; Edwardson, J. M. AFM Imaging Reveals the Tetrameric Structure of the TRPM8 Channel. Biochem. Biophys. Res. Commun. 2010, 394, 383-386.

216. Barrera, N. P.; Shaifta, Y.; McFadzean, I.; Ward, J. P. T.; Henderson, R. M.; Edwardson, J. M. AFM Imaging Reveals the Tetrameric Structure of the TRPC1 Channel. Biochem. Biophys. Res. Commun. 2007, 358, 1086-1090.

217. Liao, M.; Cao, E.; Julius, D.; Cheng, Y. Structure of the TRPV1 Ion Channel Determined by Electron Cryo-Microscopy. Nature 2013, 504, 107-112.

218. Bandell, M.; Dubin, A. E.; Petrus, M. J.; Orth, A.; Mathur, J.; Hwang, S. W.; Patapoutian, A. High-Throughput Random Mutagenesis Screen Reveals TRPM8 Residues Specifically Required for Activation by Menthol. Nat. Neurosci. 2006, 9, 493-500.

219. Rath, P.; Hilton, J. K.; Sisco, N. J.; Van Horn, W. D. Implications of Human Transient Receptor Potential Melastatin 8 (TRPM8) Channel Gating from Menthol Binding Studies of the Sensing Domain. Biochemistry 2016, 55, 114-124.

220. Taberner, F. J.; Lopez-Cordoba, A.; Fernandez-Ballester, G.; Korchev, Y.; FerrerMontiel, A. The Region Adjacent to the C-End of the Inner Gate in Transient Receptor Potential Melastatin 8 (TRPM8) Channels Plays a Central Role in Allosteric Channel Activation. J. Biol. Chem. 2014, 289, 28579-28594.

221. Pedretti, A.; Marconi, C.; Bettinelli, I.; Vistoli, G. Comparative Modeling of the Quaternary Structure for the Human TRPM8 Channel and Analysis of its Binding Features. BBA-Biomembranes 2009, 1788, 973-982.

222. Bidaux, G.; Sgobba, M.; Lemonnier, L.; Borowiec, A.-S.; Noyer, L.; Jovanovic, S.; Zholos, A. V.; Haider, S. Functional and Modeling Studies of the Transmembrane Region of the TRPM8 Channel. Biophys. J. 2015, 109, 1840-1851.

223. Yudin, Y.; Rohacs, T. Regulation of TRPM8 Channel Activity. Mol. Cell. Endocrinol. 2012, 353, 68-74. 
224. Tang, Z.; Kim, A.; Masuch, T.; Park, K.; Weng, H.; Wetzel, C.; Dong, X. Pirt Functions as an Endogenous Regulator of TRPM8. Nat. Commun. 2013, 4, 3179/1-3179/9.

225. Tang, M.; Wu, G.-y.; Dong, X.-z.; Tang, Z.-x. Phosphoinositide Interacting Regulator of TRP (Pirt) Enhances TRPM8 Channel Activity in vitro via Increasing Channel Conductance. Acta Pharmacol. Sin. 2016, 37, 98-104.

226. McKemy, D. D. The Molecular and Cellular Basis of Cold Sensation. ACS Chem. Neurosci. 2013, 4, 238-247.

227. Zhang, X.; Mak, S.; Li, L.; Parra, A.; Denlinger, B.; Belmonte, C.; McNaughton, P. A. Direct Inhibition of the Cold-Activated TRPM8 Ion Channel by Gaq. Nat. Cell Biol. 2012, 14, 851-858

228. Valente, P.; Fernandez-Carvajal, A.; Camprubi-Robles, M.; Gomis, A.; Quirce, S.; Viana, F.; Fernandez-Ballester, G.; Gonzalez-Ros, J. M.; Belmonte, C.; Planells-Cases, R.; Ferrer-Montiel, A. Membrane-Tethered Peptides Patterned after the TRP Domain (TRPducins) Selectively Inhibit TRPV1 Channel Activity. FASEB J. 2011, 25, 1628-1640, 10.1096/fj.10-174433.

229. Morenilla-Palao, C.; Pertusa, M.; Meseguer, V.; Cabedo, H.; Viana, F. Lipid Raft Segregation Modulates TRPM8 Channel Activity. J. Biol. Chem. 2009, 284, 9215-9224.

230. Saghy, E.; Szoke, E.; Payrits, M.; Helyes, Z.; Borzsei, R.; Erostyak, J.; Janosi, T. Z.; Setalo Jr, G.; Szolcsanyi, J. Evidence for the Role of Lipid Rafts and Sphingomyelin in Ca2+Gating of Transient Receptor Potential Channels in Trigeminal Sensory Neurons and Peripheral Nerve Terminals. Pharmacol. Res. 2015, 100, 101-116.

231. De Petrocellis, L.; Moriello, A. S.; Imperatore, R.; Cristino, L.; Starowicz, K.; Di Marzo, V. A Re-evaluation of 9-HODE Activity at TRPV1 Channels in Comparison with Anandamide: Enantioselectivity and Effects at other TRP Channels and in Sensory Neurons. Br. J. Pharmacol. 2012, 167, 1643-1651.

232. Fernandez, J. A.; Skryma, R.; Bidaux, G.; Magleby, K. L.; Scholfield, C. N.; McGeown, J. G.; Prevarskaya, N.; Zholos, A. V. Short Isoforms of the Cold Receptor TRPM8 Inhibit 
Channel Gating by Mimicking Heat Action Rather than Chemical Inhibitors. J. Biol. Chem. 2012, 287, 2963-2970.

233. Bidaux, G.; Borowiec, A.-s.; Gordienko, D.; Beck, B.; Shapovalov, G. G.; Lemonnier, L.; Flourakis, M.; Vandenberghe, M.; Slomianny, C.; Dewailly, E.; Delcourt, P.; Desruelles, E.; Ritaine, A.; Polakowska, R.; Lesage, J.; Chami, M.; Skryma, R.; Prevarskaya, N. Epidermal TRPM8 Channel Isoform Controls the Balance between Keratinocyte Proliferation and Differentiation in a Cold-Dependent Manner. Proc. Natl. Acad. Sci. U. S. A. 2015, 112, E3345-E3354.

234. Ghosh, D.; Pinto, S.; Danglot, L.; Vandewauw, I.; Segal, A.; Van Ranst, N.; Benoit, M.; Janssens, A.; Vennekens, R.; Vanden Berghe, P.; Galli, T.; Vriens, J.; Voets, T. VAMP7 Regulates Constitutive Membrane Incorporation of the Cold-Activated Channel TRPM8. Nat. Commun. 2016, 7, 10489.

235. Asuthkar, S.; Elustondo, P. A.; Demirkhanyan, L.; Sun, X.; Baskaran, P.; Velpula, K. K.; Thyagarajan, B.; Pavlov, E. V.; Zakharian, E. The TRPM8 Protein Is a Testosterone Receptor: I. Biochemical Evidence for Direct TRPM8-Testosterone Interactions. J. Biol. Chem. 2015, 290, 2659-2669.

236. Asuthkar, S.; Demirkhanyan, L.; Sun, X.; Velpula, K. K.; Zakharian, E.; Elustondo, P. A.; Krishnan, V.; Baskaran, P.; Thyagarajan, B.; Pavlov, E. V. The TRPM8 Protein is a Testosterone Receptor: II. Functional Evidence for an Ionotropic Effect of Testosterone on TRPM8. J. Biol. Chem. 2015, 290, 2670-2688.

237. Gkika, D.; Flourakis, M.; Lemonnier, L.; Prevarskaya, N. PSA Reduces Prostate Cancer Cell Motility by Stimulating TRPM8 Activity and Plasma Membrane Expression. Oncogene 2010, 29, 4611-4616.

238. Bonvini, S. J.; Birrell, M. A.; Smith, J. A.; Belvisi, M. G. Targeting TRP Channels for Chronic Cough: from Bench to Bedside. N-S Arch. Pharmacol. 2015, 388, 401-420.

239. Sidaway, P. Urinary Incontinence TRPM8 Influences Bladder Filling. Nat. Rev. Urol. 2015, 12, 476 . 
240. Gregorio-Teruel, L.; Valente, P.; Liu, B.; Fernandez-Ballester, G.; Qin, F.; FerrerMontiel, A. The Integrity of the TRP Domain is Pivotal for Correct TRPV1 Channel Gating. Biophys. J. 2015, 109, 529-541.

241. Bonache, M. A.; Balsera, B.; Lopez-Mendez, B.; Millet, O.; Brancaccio, D.; GomezMonterrey, I.; Carotenuto, A.; Pavone, L. M.; Reille-Seroussi, M.; Gagey-Eilstein, N.; Vidal, M.; de la Torre-Martinez, R.; Fernandez-Carvajal, A.; Ferrer-Montiel, A.; Garcia-Lopez, M. T.; Martin-Martinez, M.; de Vega, M. J. P.; Gonzalez-Muniz, R. De Novo Designed Library of Linear Helical Peptides: An Exploratory Tool in the Discovery of Protein-Protein Interaction Modulators. ACS Comb. Sci. 2014, 16, 250-258.

242. Facchinetti, F.; Patacchini, R. The Rising Role of TRPA1 in Asthma. Open Drug Discovery J. 2010, 2, 71-80. 
TOC GRAPHIC

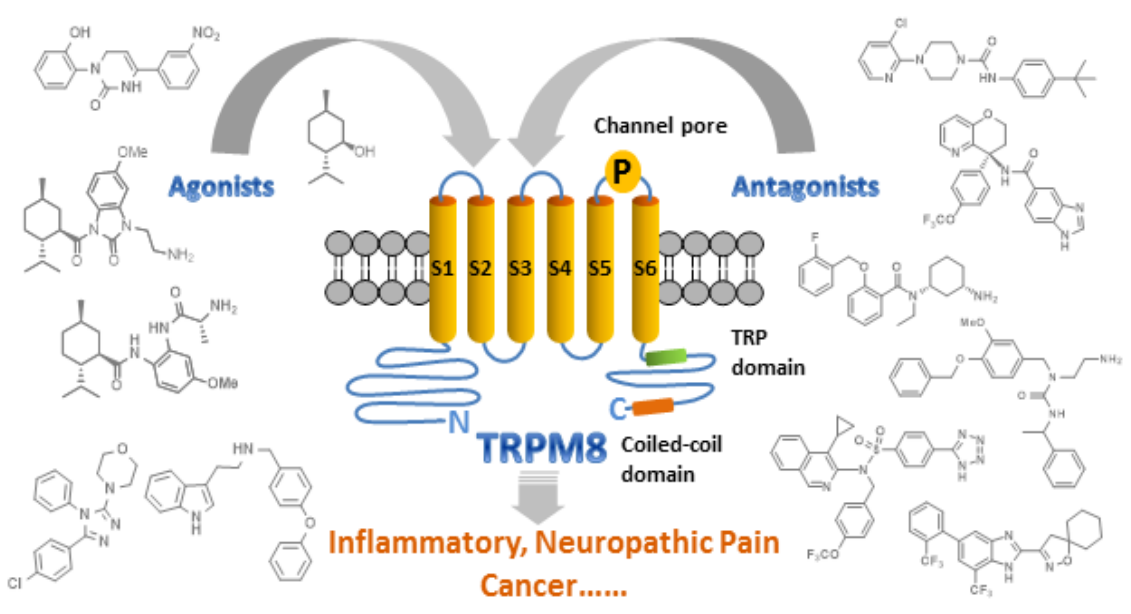

